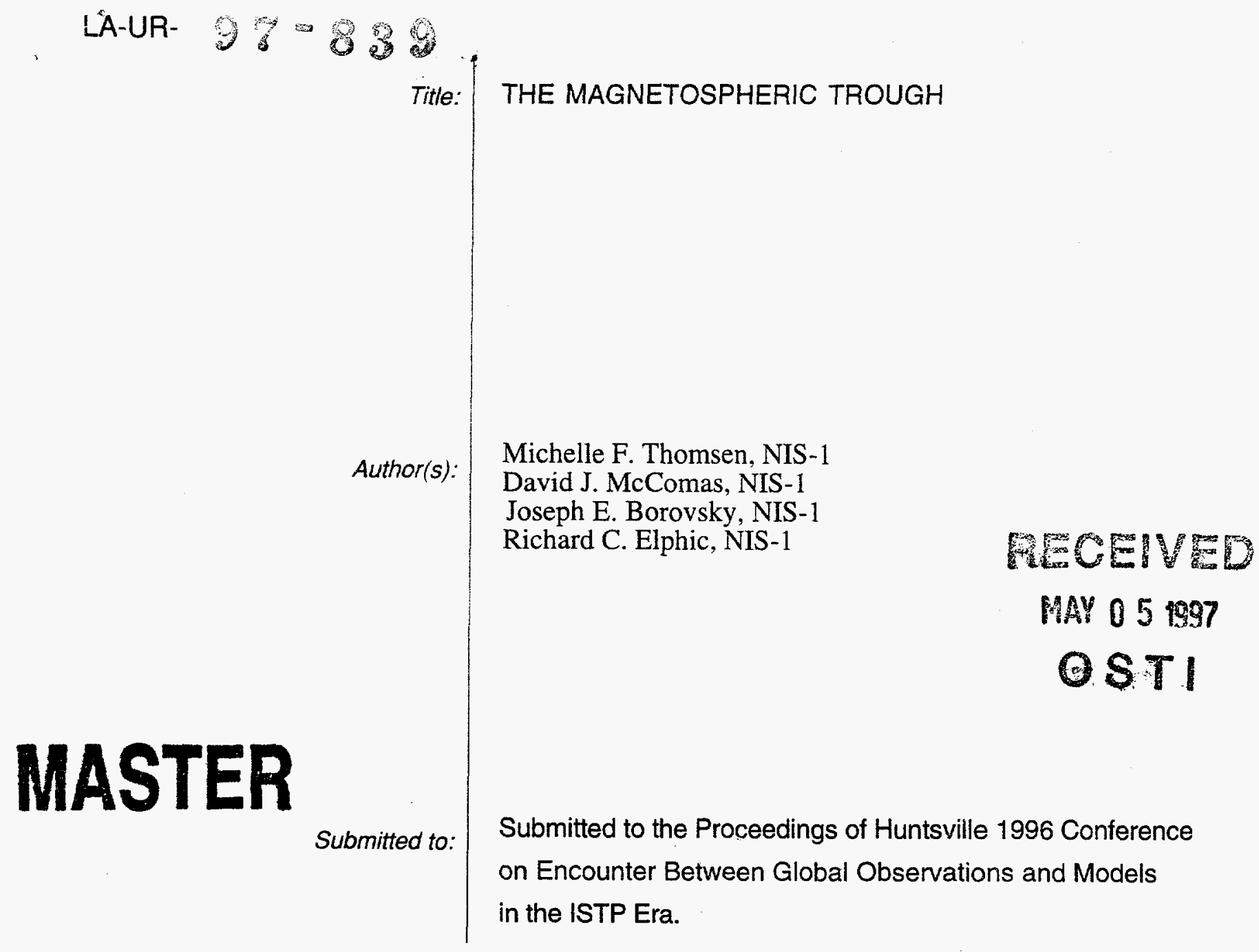

DISCLAIMER

DISTRIBUTION OF THIS DOCUMENT IS UNLIMITEI HH

This report was prepared as an account of work sponsored by an agency of the United States Government. Neither the United States Government nor any agency thereof, nor any of their employees, makes any warranty, express or implied, or assumes any legal liability or responsibility for the accuracy, completeness, or usefulness of any information, apparatus, product, or process disclosed, or represents that its use would not infringe privately owned rights. Reference herein to any specific commercial product, process, or service by trade name, trademark, manufacturer, or otherwise does not necessarily constitute or imply its endorsement, recommendation, or favoring by the United States Government or any agency thereof. The views and opinions of authors expressed herein do not necessarily state or reflect those of the United States Government or any agency thereof.
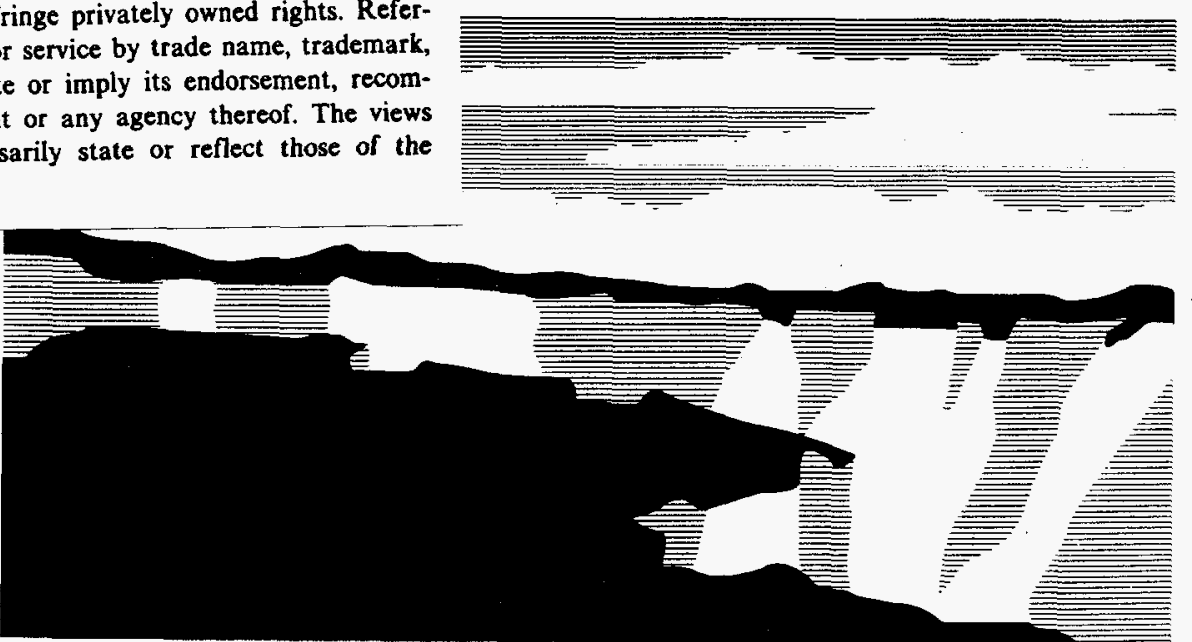

Los Alamos National Laboratory, an affirmative action/equal opportunity employer, is operated by the University of California for the U.S. Department of Energy under contract W-7405-ENG-36. By acceptance of this article, the publisher recognizes that the U.S. Government retains a nonexclusive, royalty-free license to publish or reproduce the published form of this contribution, or to allow others to do so, for U.S. Government purposes. The Los Alamos National Laboratory requests that the publisher identify this article as work performed under the auspices of the U.S. Department of Energy. 


\section{DISCLAMIER}

Portions of this document may be illegible in electronic image products. Images are produced from the best available original docament. 


\title{
The Magnetospheric Trough
}

\section{F. Thomsen. D. J. McComas. J. E. Borovsky. and R. C. Eiphic} Los Alamos National Laboratory, Los Alamos. NM

for submission to the Proceedings of the Huntsville 1996 Conference on Encounter Between Global Observations and Models in the ISTP Era

March 4. 1997

\begin{abstract}
We review the history of the concepts of the magnetospheric coid-ion trough and hot-electron trough and conclude that the two regions are actually essentiaily the same. The magnetospheric trough may be viewed as a temporal state in the evolution of convecting flux tubes. These flux tubes are in contact with the earth's upper atmosphere. which acts both as a sink for precipitating hot plasma sheet electrons and as a source for the cold ionospheric plasma. leading to progressive depletion of the plasma sheet and refilling with cold plasma. Geosynchronous plasma observations show that the rate of loss of plasma-sheet electron energy density is commensurate with the precipitating electron flux at the low-latitude edge of the diffuse aurorae. The rate at which geosynchronous flux tubes fill with coid ionospheric plasma is found to be consistent with previous estimates of early-time refilling. Geosynchronous observations further indicate that both Coulomb collisions and wave-particle effects probably play a role in trapping ionospheric material in the magnetosphere.
\end{abstract}

1. Introduction

\section{I Ion trough}

When the plasmasphere and plasmapause were discovered in the early sixties through satellite measurements and ground-based whistler wave studies [e.g., Gringauz et al., 1960; Carpenter, 1962; Carpenter, 1966], the low-density region immediately outside the dense plasmasphere was termed the "plasma trough" [Carpenter, 1966]. Whistler measurements revealed not only the existence of the plasma trough, but the fact that the 
density in the nightside trough was typically lower than that in the dayside trougn [Angerami and Carpenter. 1966]. With observations from the Lockheed light ion spectrometer on Ogo 5. Chappeil et al. [1971] showed that in addition to the dav/night asymmetry, there is a local time gradient in the dayside trough density, from low vaiues near dawn to increasingly larger values througn noon toward evening. They interpreted this gradient as a progressive filling of the flux tubes with outflowing ionospheric material as the flux tubes convect across the dayside magnetosphere. Figure 1. from Chappell et al. [1971], illustrates the morning-to-evening density gradient at $L=5$ (ieft panel) and the convection/filling interpretation (right panel).

The convection pattern underlying the Chappeil et ai. explanation was based on the models proposed earlier by Axford and Hines [1961], Carpenter [1962], Nishida [1966], and Brice [1967]. This basic pattern, illustrated in Figure 2, arose from the superposition of a dawn-to-dusk electric field imposed across the magnetosphere by the solar wind and a corotational electric field imposed by the ionosphere. The resuitant cold plasma flow paths (i.e., the equipotentials of the total electric field) form two ciasses: paths that close around the earth, and open paths that enter from the night side and exit through the dayside magnetopause. The location of the separatrix between the two is determined by the strength of the imposed convection, being closer to the earth for stronger convection. This simple picture accounted nicely for the existence of the plasmasphere, including its dusk bulge [Nishida, 1966].

The second component of the Chappell et al. [1971] explanation of the dayside trough was that of flux tube filling from the ionosphere during the convection process. Flux tubes following closed drift paths around the earth remain exposed to the ionospheric source for long periods of time, resulting in the accumulation of large cold plasma densities (the plasmasphere). Flux tubes on open trajectories are exposed only for the time it takes them to move through the dayside magnetosphere. The ionospheric source was described theoretically in terms of a hydrodynamic model by Banks et al. 
[1971], based on a similar approach to describe the polar wind [Banks and Hoizer. 1969]. The filling process. including mechanisms by which outflowing ionospheric material can be trapped in the magnetosphere. is a topic of considerable interest [c.f.. the February, 1992, special section of J. Geophys. Res., especially the introductory review by Horwitz and Singh].

\subsection{Electron trough}

In the same time frame in which the morphology and properties of the cold ion trough were being investigated. interest was also focused on the nightside plasma sheet. including its inner (earthward) edge. Frank [1971] summarized the spatial reiationship of several magnetospheric boundaries, including the inner edge of the nightside plasma sheet. Using Ogo 3 measurements, he found that in the midnight region the inner edge of the plasma sheet often abuts the plasmapause, but prior to local midnight there appears to be a significant gap between the two (see Figure 3, from Frank [1971]). The gap between the plasmapause and the earthward edge of the plasma sheet was iermed the eiectron "trough." This gap was consistent with the earlier results of Vasyliunas [1968], who reported that in the local time range of 17-22 hours, "weak or no electron fluxes are found between the inner boundary of the plasma sheet and the outer boundary of the plasmasphere."

This region was revisited by Fairfield and Viñas [1984] using ISEE-1 low-energy electron measurements. They confirmed the earlier findings that the piasma sheet abuts the plasmapause post-midnight and that a gap between the two commonly exists in the premidnight region. The explanation they proposed for this gap is illustrated in Figure 4. Comparison with Figure 2 shows that the explanation depends on the same flux-tube convection pattern responsible for ion trough filling. As flux tubes convect from the tail into and around the near-earth region, they begin to lose their load of hot plasma-sheet electrons through precipitation into the atmosphere. This precipitation is responsible for 
the diffuse aurora [Fairfield and Viñas, 1984] and resuits in significant depletion by the time the flux tubes reach the afternoon/evening sector. Fairfieid and Viñas proposed that a spacecraft exiting from the plasmasphere in the evening sector could pass through $a$ region of depleted flux tubes before entering the "fresn" plasma sheet on flux tubes that are newly arrived from the tail. In this picture. the evening "trough" between the plasmasphere and plasma sheet is simply a natural extension of the region of depleted electron fluxes in the afternoon sector. Hence, it would be appropriate to expand the use of the term "trough" to cover the full depieted sector, and this is the approach we adopt here.

In a later study based on DE-1 and DE-2 data, Horwitz et al. [1986] found no systematic evidence for a separation between the plasmapause and the plasma sheet in the evening sector and suggested that the gap found in the various earlier studies may have been the result of using $1-\mathrm{keV}$ electrons rather than $100-\mathrm{eV}$ electrons to mark the inner edge of the plasma sheet. Horwitz et al. [1986] thus called into question the existence of the original electron "trough," i.e., the extension of the afternoon depleted region into the evening sector beyond the plasmasphere bulge, as illustrated in Figure 4. The electron trough defined more broadly to apply to the entire afternoon region of lower electron fluxes is, however, well explained by the interpretation offered by Fairfield and Viñas (Figure 4).

\subsection{Synthesis}

The historical development sketched above brings us to the conclusion that the ion and electron trough regions, on the surface apparently different entities, are in reality physically the same. Moreover, the underlying physical picture suggests that the magnetospheric trough should be viewed not so much as a spatial region, but as a temporal state in the evolution of convecting flux tubes that are in contact with the earth's upper atmosphere. The atmosphere acts both as a sink for precipitating hot plasma sheet 
electrons and as a source for the cold ionospheric plasma. leading to progressive depletion of hot plasma sheet electrons and refilling with cold plasma. Figure 5 schematically summarizes this picture. The two paneis (ion trough and electron trough) are essentially mirror images. In reality of course, this simpie picture is compiicated by temporal changes in the convection pattern and in the precipitation and filling rates. It is further modified by divergence of hot electron drift paths from the ExB drift vaths of the cold plasma. due to gradient and curvature contributions to the drift. Nonetheless. Figure 5 provides a useful conceptual framework from which to examine the physics of the trough region.

As indicated in the historical discussion above. the trough has been observed with ground-based whistler measurements and numerous satellites. Elliptically orbiting satellites such as the Ogo satellites [e.g., Vasyliunas. 1968; Frank, 1971: Chappell et al., 1971], the ISEE satellites [e.g., Carpenter and Anderson, 1992], DE [e.g., Sojka et al.. 1983], and Exos D [e.g., Watanabe et al., 1992] provide a radial cut through the plasmasphere. plasmapause. and trough, with local time information accumulated through the seasonal evolution of the orbit. A complementary view is provided by geosynchronous satellites [e.g., Lennartsson and Reasoner, 1978; Higel and Wu, 1984; McComas et al., 1993; Moldwin et al., 1994], which sample all local times within 24 hours, but only at the radial distance of $6.6 \mathrm{Re}$. In the following sections we present some illustrative examples of trough observations at geosynchronous orbit and of the physical issues that can be addressed with those observations.

\section{Geosynchronous observations}

As discussed above. the configuration illustrated in Figure 5 changes size and shape according to the strength of the convection electric field. A geosynchronous satellite will therefore find the system in different states over the course of time. Figure 6 shows our schematic configuration with three different circular orbits to illustrate the 
different sequences of regions that a geosynchronous satellite might observe. depending on the strength of the convection. A satellite travelling the orbit illustrated in the left panel would pass from the dayside trough region into the evening bulge of the plasmasphere and then out of the piasmasphere directly into the nightside piasma sheet. The center panel illustrates the case when the convection is strong enough that the plasmapause shrinks inside of the satellite orbit. In this case. the sateilite would cross the afternoon separatrix from the dayside trough to the nightside plasma sheet without ever encountering the plasmasphere. Finally, the right panel illustrates the situation when an interval of strong convection is followed by an interval of quieting, in which a new separatrix forms beyond the old piasmapause. and flux tubes that had previously been part of the dayside trough can now drift on closed trajectories on into the night side. Although not illustrated in Figure 6, another case that can occur is when the convection is weak for several days, allowing the plasmasphere to fill up to beyond geosynchronous orbit. In that case the satellite would remain within dense, cold plasmaspheric plasma throughout an entire day.

Figure 7 shows representative geosynchronous plasma observations for a case such as that illustrated in the left-hand panel of Figure 6. The data shown here and in subsequent figures were obtained by one of the Los Alamos magnetospheric plasma analyzers (MPA) now operating in geosynchronous orbit [c.f., McComas et al., 1993]. The MPAs are spherical sector electrostatic analyzers that measure the three-dimensional velocity-space distributions of ions and electrons over the nominal energy-per-charge range of $\sim 1 \mathrm{~V}$ to $40 \mathrm{kV}$. Further details on the instrument are provided by Bame et al. [1993]. Figure 7 shows 24 hours of observations of ions (upper panel) and electrons (lower panel) from the MPA on spacecraft 1994-084 on June 17, 1996. Both panels present the color-coded logarithm of the instrument count rate (proportional to the measured energy flux) as a function of the logarithm of the particle energy on the vertical 
axis and time along the horizontal axis. The measurements shown in Figure $\vec{i}$ were obtained in the southward-viewing quadrant of the satellite spin.

Figure 7 illustrates the appearance of several different magnetospheric regions at geosynchronous orbit. In the top (ion) panel. the popuiation at the highest energtes (above $\sim 10 \mathrm{keV}$ ) is the low-energy edge of the ion piasma sheet/ring current. $-t$ low ion energies between 0930 and 1500 UT, there is a very dense. cold population that we identify as plasmaspheric plasma [c.f.. McComas. et al.. 1993: Moldwin. er ai.. 994]. Just prior to this plasmaspheric interval, there are several hours of low-density. lowenergy ions that appear to build up as the satellite traverses the day side. This is the classic appearance of the dayside ion trough at geosynchronous orbit. When the satellite leaves the dense plasmasphere just before $1500 \mathrm{UT}$, it enters immediately into a region of fairly dense hot electrons ( $\sim$ several $\mathrm{keV}$ ), which is the nightside plasma sheet. This population seems to be refreshed several times as the satellite passes through the night hours, but after local dawn $(-2300$ UT), the hot electron fluxes decline steadily on into the next day, as shown in Figure 8, which presents the MPA observations for June 18. 1996.

The measurements shown in Figure 8 are representative geosynchronous plasma observations for a case such as that illustrated in the center panel of Figure 6. in which the satellite enters the nightside plasma sheet directly from the dayside trough, without ever passing through the plasmasphere extension. The decline of hot electron fluxes and the gradual increase in cold ions in the dayside trough are similar to those seen on the previous day (Figure 7), but in Figure 8 the satellite enters into the fresh plasma sheet from the trough at $\sim 1640 \mathrm{UT}$, without encountering any cold, dense, plasmaspheric ions.

The upper panel of Figure 9 shows the densities derived from the MPA cold-ion and hot-electron measurements shown in Figures 7 and 8. These densities represent numerical sums over the measured distribution functions from $E_{\mathrm{i}} \sim 1 \mathrm{eV}$ to $\sim 100 \mathrm{eV}$ and from $E_{\mathrm{e}} \sim 30 \mathrm{eV}$ to $\sim 40 \mathrm{keV}$, respectively [cf., Thomsen et al., 1996]. To draw attention to 
the dayside trough, horizontal bars have been added to show the range of UT during which the satellite travelled from $06 \mathrm{LT}$ to $18 \mathrm{LT}$ on these two days. The decrease of the hot electron density and the simultaneous increase of the cold ion density across the day side of the orbit can be seen on both June 17 and 18 .

The lower panei of Figure 9 shows the energy density of the hot electron component for the same two days. The loss of plasma sheet energy density in the morning hours is a clear signature of the development of the electron trough. In the discussion below, we will compare the loss of plasma sheet energy with the energy deposited in the atmosphere by diffuse aurorae.

The cold ion densities plotted in Figure 9 are somewhat uncertain due to uncertainties in the potential of the satellite, including possible surface charging asymmetries. A number of lines of evidence suggest that, especially at low densities $\left(<10 \mathrm{~cm}^{-3}\right)$, our moments calculation may be underestimating the cold ion population. For example, an examination of the density measured as the satellite passed through eclipse on various occasions suggests that the density computed from measurements made in sunlit conditions may be underestimated by factors of $\sim 1.2-4$ for computed densities less than $10 \mathrm{~cm}^{-3}$. A comparison between the median MPA cold ion densities measured as a function of local time for several months in 1990-91 and the median cold plasma densities measured by the GEOS 1 mutual impedance probe during 1977-78 [Decreau et al., 1982] leads to a similar conclusion.

An example of data from the type of orbit illustrated in the right-hand panel of Figure 6 is presented in Figure 10. In this example, from June 7, 1996, the satellite never enters the fresh plasma sheet on the night side, but remains within the trough region of increasing cold ions and decreasing hot electron fluxes. The electron plasma sheet population trapped on these temporarily closed drift paths has been called the "remnant layer" by Feldstein and Galperin [1985], who related it to the region of diffuse aurorae equatorward of the discrete auroral oval. 
The types of orbits described schematicaliy in Figure 6 and illustrated in Figures 7-10 are quite commonly observed at geosynchronous orbit. confirming the general utility of the concepts summarized in Figure 5. There are occasions. however. when the geosynchronous observations do not fit neatly into this basic framework. Figures 11 and 12 illustrate two such examples. Figure 11, from July 6. 1996. is quite similar to Figure 8 in that the satellite leaves the dayside cold-ion trough (at $~: 200 \mathrm{LT}$ ) without encountering any dense. cold, plasmaspheric plasma. It wouid thus appear to be a case of crossing the afternoon separatrix, as in the center panel of Figure 6. However, unlike Figure 8 and unlike what one might expect on the basis of Figure 6. the satellite does not obviously observe fresh plasma sheet electrons upon crossing the separatrix. Rather. there is a 2-3 hour interval of trough-like electron fluxes. but with no corresponding cold ions, before the satellite clearly encounters the evening plasma sheet at $\sim 14-15$ UT. Close inspection of this trough-like interval, however, shows that it does contain a very tenuous, cool, plasma-sheet-like electron population (note that we have adjusted the color bar for the electrons to bring out these very low fluxes), and it is possible to reconcile this event with the expectations of Figure 6 if one assumes that the plasma sheet in this region was extremely weak at this time. One possible explanation for the low density might be that these plasma sheet flux tubes, while nominally on open drift trajectories (c.f., Figure 6), may have spent a long time in the dusk stagnation region and have consequently suffered appreciable losses to atmospheric precipitation. It may be that a similarly tenuous (depleted?) plasma sheet was responsible for some of the gaps between the plasmapause and the inner edge of the plasma sheet reported by Vasyliunas [1968] and by Frank [1971].

Figure 12, from January 1, 1996, shows another example that appears to be at odds with the predictions of Figure 6, namely, a case in which essentially no cold ion trough was seen across the entire day side of the orbit. Such events can potentiaily shed 
light on what controls the uprlow of ionospheric materiai into the equatorial magnetosphere.

\section{Trough physics}

\subsection{Plasma sheet electron iosses}

As suggested by Fairfield and Viñas [1984], the decline in the piasma sheet electron content as flux tubes drift from the near-earth tail on the night side around onto the day side is due to the precipitation of the piasma sheet electrons into the ionosphere, producing the morning-side diffuse aurora. We can estimate the rate of energy deposition into the ionosphere by measuring the typical rate at which the plasma sneet electron energy density declines as a function of local time. Figure 13 shows the local time dependence of the density, temperature, and energy density (defined as the density times the temperature) of electrons between $\sim 30 \mathrm{eV}$ and $\sim 40 \mathrm{keV}$ as measured by the MPA on 1989-046 during the month of January 1990. The decline of the energy density past midnight is quite clear. Figure 14 shows the local time dependence of the various percentile levels of the energy density in one-hour local-time bins for the same month of data. A linear fit to the 25 th, 50 th, and 75 th percentile levels between 01 and 09 LT yields values of $-95,-170$, and $-212 \mathrm{eV} \mathrm{cm}^{-3}$ per hour of local time, respectively, for the slopes of the curves. To convert this spatial loss rate to a temporai loss rate. we use the azimuthal drift speed of $2 \mathrm{keV}$ electrons, a typical plasma sheet temperature (Figure 13), which for corotation plus gradient and curvature drift in a dipole field is 1.43 hours of local time per hour. Thus the temporal loss rates for plasma sheet electron energy density between 01 and $09 \mathrm{LT}$ in Figure 14 are 135, 243, and $303 \mathrm{eV} \mathrm{cm}^{-3} \mathrm{hr}^{-1}$ for the 25 th, 50 th, and 75 th percentile levels, respectively.

The temporal loss rate of plasma sheet energy density, $\mathcal{E}$, is related to the energy flux into the ionosphere, $\mathcal{F}$,

$$
(\partial / \partial \mathrm{t}) \int \mathcal{E} \mathrm{d}^{3} \mathrm{~V}=2 \int \mathcal{F} \mathrm{dA}
$$


where the integrai on the left-hand side is over the volume of a given tlux tube. and the integral on the right-hand side is over the cross-sectional area of the same flux tube at the ionosphere. If we assume that the electron energy density is roughly a constant aiong the flux tube and approximate the field as a dipole. we have

$$
\mathcal{F}=\left(1.05 \times 10^{12} \mathrm{~cm}\right)(\partial \mathcal{E} / \partial \mathrm{t})
$$

Thus, the 50th percentile level in Figure 14 implies a precipitating electron energy flux of $0.11 \mathrm{erg} \mathrm{cm}^{-2} \mathrm{~s}^{-1}$. For comparison. Spiro et al. [1982] found the quiet-time mean energy flux of precipitating electrons at low altitudes to be in the range $0.2-1.0 \mathrm{erg} \mathrm{cm}^{-2} \mathrm{~s}^{-1}$

between 01 and $09 \mathrm{LT}$ at a geomagnetic latitude of $67^{\circ}$, the nominal invariant latitude for geosynchronous orbit in a dipole field. However, recent studies comparing geosynchronous plasma measurements with similar measurements made with DMSP at low altitudes [Weiss et al., 1996: Reeves et al., 1997] suggest that the typical ionospheric magnetic latitude to which geosynchronous orbit maps in the post-midnight region is generally lower than $67^{\circ}$ by a few degrees. At a magnetic latitude of $64^{\circ}$. Spiro et al. [1982] find mean energy fluxes between 0.05 and $0.17 \mathrm{erg} \mathrm{cm}^{-2} \mathrm{~s}^{-1}$. in very good agreement with the estimate based on the geosynchronous observations.

\subsection{Plasmasphere refilling}

One of the earliest objectives of studies of the cold ion trough was the question of how rapidly flux tubes could fill with upflowing ionospheric material [e.g., Angerami and Carpenter, 1966; Chappell, et al., 1971]. Because it is one of the most fundamental examples of ionosphere/magnetosphere coupling, this issue is still of high interest. The question of plasmaspheric refilling has two aspects: 1) What is the rate at which material flowing up from the ionosphere fills the flux tubes? and 2) What are the mechanisms responsible for trapping that material in the magnetosphere? Geosynchronous observations can help address both issues: 
3.2.1 Refilling rate. Because the tlux tubes of the dayside plasma trough are approximately corotating, the spatiai gradients in coid piasma density that are typicaily observed at geosynchronous orbit across the day side can be converted to temporal filling rates. This approach has been used by severai authors ie.g., Park. 1970: Park. 1974: Higel and Wu, 1984: Sojka and Wrenn. 1985: Song et al.. 1988: Furrugia et al.. 1989]. During steady magnetospheric conditions. this can be cone for an individual orbit te.g.. Figure 9); more generally, because of temporai variations in the convection pattern. this estimation of the filling rate can be done statistically. In Figure 15 we show the occurrence frequency distribution for the cold ion density measured at geosynchronous orbit by the MPA on spacecraft 1989-046 during the month of July, 1990. The data have been sorted by local time of observation. with the distribution for every other one-hour bin across the day-side filling region stacked vertically. For comparison. the distribution for the 05-06 LT bin is repeated as the light curve in each panel. The tick marks at the top of each panel mark the 25th percentile values of the measured density for each distribution. It is clear from Figure 15 that the cold plasma density increases systematically across the dayside trough, from values of less than $1 \mathrm{~cm}^{-3}$ before dawn to roughly $1.5 \mathrm{~cm}^{-3}$ in the afternoon.

In Figure 16 we plot the value of the cold-ion density at various percentile levels in each one-hour local time bin for the same month of data. For comparison. we also plot as the light dashed line the curve derived from the plasma trough model of Carpenter and Anderson [1992], evaluated at $L=6.6$. Since the Carpenter and Anderson values represent total electron density (cold plus hot), we also show as the heavier dashed line their curve reduced by $0.7 \mathrm{~cm}^{-3}$, a representative value for the hot plasma sheet ion density.

An analysis like that illustrated in Figure 16 has been done for 11 different months of data, from different seasons and different parts of the solar cycle. and the resulting 25 th and 50th percentile levels for the 12-13 LT bin are plotted in Figure 17. The 50th percentile levels tend to vary erratically from month to month because of the 
variable probability of encountering the dense piasmasphere near noon. but there is a remarkable steadiness to the 25 th percentile level. which we theretore take to be a good measure of the true trough density, uncontaminated by dense intervais. These measured values tend to be lower than the 12 LT trough density given by the Carpenter and Anderson relation (see Figure 16) by factors of $-1-3$. As discussed earlier, there is reason to believe that the computed MPA coid ion densities may be underestimated by a similar factor when the density is low $\left(<10 \mathrm{~cm}^{-3}\right)$. With such a correction. the trough densities we observe are quite consistent with the Carpenter and Anderson relation.

To estimate the filling rate from the spatial gradient of the observed coid ion density, we use the lower percentile levels shown in Figure 16 since these presumably represent the "freshest" trough flux tubes, i.e.. those which are executing their first pass across the dayside region. Under the assumption that the flux tubes are approximately corotating (i.e., traverse one hour of local time in one hour of actual time), the slopes of the 5 th, 25 th and 50 th percentile levels in Figure 16 correspond to filling rates of 0.085 , 0.124 , and $0.218 \mathrm{~cm}^{-3} \mathrm{hr}^{-1}$, respectively (where the slopes are taken between 04 and 14 LT). If the filling is assumed to occur only on the day side (i.e., when the ionospheric footpoints are illuminated), these correspond to approximate daily filling rates of $1.0,1.5$. and $2.6 \mathrm{~cm}^{-3}$ day -1 , respectively. This can be compared to the values $0.287 \mathrm{~cm}^{-3} \mathrm{hr}^{-1}$ or $3.4 \mathrm{~cm}^{-3}$ day $^{-1}$ determined by Carpenter and Anderson [1992].

Table 1 summarizes hourly filling rates derived in this fashion from the 25 th percentile levels for the eleven different months of observations. The 25 th percentile level was chosen because it seems to correspond fairly well to the peak of the low-density end of the hourly distributions (see Figure 15) and appears to be uncontaminated by encounters with the dense plasmasphere (see Figure 17). The months included in Table 1 represent northern winter, summer, and fall conditions near solar maximum (1990-91) and near solar minimum (1995-96). These months provide a crude exploration of seasonal and solar cycle dependences [c.f., Carpenter and Anderson, 1992; Rasmussen et 
al.. 1993]. From Table 1 it appears that the refilling rate ranges from about 0.05 to 0.25 $\mathrm{cm}^{-3} \mathrm{hr}^{-1}$, with no strong indication of either seasonal or solar cycle dependence. With the increase of a factor of $\sim 1.2-4$ discussed above. the derived refilling rates are consistent with the Carpenter and Anderson vaiue.

Table 1. Derived Refilling Rates

\begin{tabular}{lcc}
\hline Spacecraft & Month & Rate $\left(\mathrm{cm}^{-3} \mathrm{hr}^{-\mathrm{i}}\right)$ \\
\hline $1989-046$ & January 1990 & 0.049 \\
$1989-046$ & July 1990 & 0.124 \\
$1989-046$ & September 1991 & 0.100 \\
$1990-095$ & September 1991 & 0.078 \\
$1989-046$ & December 1991 & 0.136 \\
$1990-095$ & December 1991 & 0.076 \\
$1991-080$ & January 1996 & 0.070 \\
$1994-084$ & January 1996 & 0.140 \\
$1994-084$ & June 1996 & 0.250 \\
$1994-084$ & July 1996 & 0.146 \\
$1990-095$ & September 1996 & 0.184 \\
\hline
\end{tabular}

3.2.2 Trapping mechanisms. There are several mechanisms that might be operating to trap upflowing ionospheric material in the magnetosphere. One such mechanism is due to electromagnetic ion cyclotron waves driven by the hot ring-current ion temperature anisotropy; these waves have been observed to cause transverse heating of cool ions [Mauk and McPherron, 1980; Young et al., 1981], thereby increasing their pitch angles and trapping them in the magnetospheric "bottle." In support of this mechanism, Gary et al. [1994, 1995] have shown that the geosynchronous hot-ion temperature anisotropy has an upper bound that obeys the scaling relationship expected 
for this instability on theoretical grounds. Moreover. the mechanism accounts for the warm $(10 \mathrm{eV})$ ion population often seen in the afternoon trough region and characterized by strong $T_{\perp}>T_{||}$temperature anisotropies [Olsen. 1981: Gary et al.. 1997], quite in contrast to the field-aligned nature of cool ion outflows observed in the morning sector. The consequences of the presence of such warm, equatoriaily trapped ions for the further trapping of ionospheric upflows have been addressed by Singh and Chan [19921.

Another mechanism that can be important in trapping ionospheric uptlows is Coulomb collisions [e.g., Schulz and Koons. 1972: Lemaire. 1989: Wilson et al.. 1992], which become increasingly important as a tlux tube tills with plasma. The numerical simulations of Wilson et al. [1992] show that Coulomb collisions not only increase the filling rate, but they produce a characteristic two-stage filling process as seen at the magnetic equator: At early times, the plasma flowing up from the ionospheric footpoints of a given flux tube exhibits a large parallel temperature anisotropy all along the flux tube. As the density builds up in the flux tube, two regions of near-isotropy develop at the ionospheric ends. and these regions expand up aiong the flux tube until they meet at the equator. At this point, which at $L=6$ is after about 28 hours of refilling for the outflow parameters used by Wilson et al., the plasma at the equator is nearly isotropic. Beyond this time the apparent refilling rate at the equator $(\mathrm{dn} / \mathrm{dt})$ increases markedly. In the $\mathrm{L}=6$ simulation, Wilson et al. found an equatorial density of about $8 \mathrm{~cm}^{-3}$ after the first 24 hours, with a subsequent increase to $30 \mathrm{~cm}^{-3}$ in the next 24 hours.

There are at least two pieces of observational evidence from geosynchronous orbit that support this picture. First, there is the difference between the early-time filling rates estimated above and by several previous authors based on dayside trough density observations, which are typically in the range of several particles per $\mathrm{cm}^{3}$ per day, and the late-time filling rates estimated to be in the range of $30-50 \mathrm{~cm}^{-3}$ per day [Sojka and Wrenn, 1985; D. Lawrence, personal communication]. Second, there is the fact that at low trough densities the low-energy ion distributions are typically field-aligned, 
becoming nearly-isotropic at densities $\sim 10-100 \mathrm{~cm}^{-3}$ [e.g. Nagai et al.. 1985: Horwitz et al., 1990]. In agreement with these earlier studies. Los Alamos geosynchronous observations indicate that this transition occurs at cold ion densities near $10 \mathrm{~cm}^{-3}$.

\section{Summary}

Recent geosynchronous plasma measurements complement and contirm earlier observations of the magnetospheric trough. The separately described cold-ion and hotelectron troughs are in reality the same region. The magnetospheric trough is not so much a spatial region as a temporal state in the evolution of convecting flux tubes that are in contact with the earth's upper atmosphere. The atmospinere acts both as a sink for precipitating hot plasma-sheet electrons and as a source for the cold ionospheric plasma. leading to progressive depletion of plasma sheet content and filling with cold plasma. The rate of depletion of hot electron energy density at geosynchronous orbit is commensurate with the precipitating electron flux at the low-latitude edge of the diffuse aurorae, and the measured rates of cold-ion density build-up are in general agreement with previous estimates of early-time flux-tube refilling. Geosynchronous observations further indicate that transverse heating of upflowing ionospheric ions by electromagnetic ion cyclotron waves produced by the hot ring-current temperature anisotropy may contribute to cold-ion trapping in the magnetosphere. In addition. at least two lines of evidence indicate that Coulomb collisions play a prominent role in trapping the new material.

Acknowledgments. We are grateful to our colleagues at Los Alamos for numerous very helpful discussions and suggestions. We also thank Jim Horwitz for his interest and encouragement. This work was performed under the auspices of the U. S. Department of Energy with support from the NASA ISTP program. 


\section{References}

Angerami, J. J., and D. L. Carpenter. Whistler studies of the piasmapause in the magnetosphere 2. Electron density and total tube electron content near the knee in magnetospheric ionization. J. Geophys. Res., 71, 711, 1966.

Axford, W. I., and C. O. Hines, A unifying theory of high latitude geopnysical phenomena and geomagnetic storms, Can. J. Phys., 39. 1433. 1961.

Bame, S. J., et al., Magnetospheric plasma analyzer for spacecraft with constrained resources. Rev. Sci. Instrum. 64, 1026, 1993.

Banks, P. M., and T. E. Holzer. High-latitude plasma transport: The poiar wind. $J$. Geophys. Res., 74. 6317. 1969.

Banks, P. M., A. F. Nagy, and W. I. Axford, Dynamical behavior of thermal protons in the mid-latitude ionosphere and magnetosphere. Planet. Space Sci.. 19. 1053. 1971.

Brice, N. M., Bulk motion of the magnetosphere, J. Geophys. Res.. 72. 5193, 1967.

Carpenter, D. L., New experimental evidence of the effect of magnetic storms on the magnetosphere, J. Geophys. Res., 67, 135, 1962.

Carpenter, D. L., Whistler studies of the plasmapause in the magnetosphere 1. Temporal variations in the position of the knee and some evidence on plasma motions near the knee, J. Geophys. Res., 71, 693, 1966.

Carpenter, D. L., and R. R. Anderson, An ISEE/whistler model of equatorial electron density in the magnetosphere, J. Geophys. Res. 97, 1097, 1992.

Chappell, C. R., K. K. Harris, and G. W. Sharp, The dayside of the plasmasphere, J. Geophys. Res., 76, 7632, 1971.

Decreau, P. M. E., C. Beghin, and M. Parrot, Global characteristics of the cold plasma in the equatorial plasmapause region as deduced from the GEOS 1 mutual impedance probe, J. Geophys. Res., 87, 695, 1982.

Fairfield, D. H., and A. F. Viñas, The inner edge of the plasma sheet and the diffuse aurora, J. Geophys. Res., 89, 841, 1984.

Farrugia, C. J., D. T. Young, J. Geiss, and H. Balsiger, The composition, temperature, and density structure of cold ions in the quiet terrestrial plasmasphere: GEOS 1 results, J. Geophys. Res., 94, 11, 1989.

Feldstein, Y. I., and Y. I. Galperin, The auroral luminosity structure in the high-latitude upper atmosphere: Its dynamics and relationship to the large-scale structure of the Earth's magnetosphere, Rev. Geophys., 23, 217, 1985.

Frank, L. A., Relationship of the plasma sheet, ring current, trapping boundary, and plasmapause near the magnetic equator and local midnight, J. Geophys. Res., 76, $2265,1971$. 
Gary, S. P., M. B. Moldwin, M. F. Thomsen, and D. Winske. Hot proton anisotropies and cool proton temperatures in the outer magnetosphere. J. Geophys. Res. 99. 23. 1994.

Gary, S. P., M. F. Thomsen, J. Lee, D. J. McComas. and K. Moore, Warm protons at geosynchronous orbit, J. Geophys. Res., submitted. 1997.

Gary, S. P., M. F. Thomsen. L. Yin, and D. Winske, Electromagnetic proton cyciotron instability: Interactions with magnetospheric protons, J. Geophys. Res., 100. 21, 1995.

Gringauz, K. I., V. G. Kurt, V. I. Moroz. and I. S. Shklovskii, Resuits of observations of charged particles observed out to $R=100,000 \mathrm{~km}$. with the aid of charged-particle traps on Soviet space rockets, Astron. Zh. 37, 4, 716, 1960.

Higel, B., and L. Wu, Electron density and plasmapause characteristics at 6.6 Re: A statistical study of the GEOS 2 relaxation sounder data, J. Geophys. Res., 89. 1583. 1984.

Horwitz, J. L., R. H. Comfort, and C. R. Chappell. A statistical characterization of plasmasphere density structure and boundary locations, J. Geophys. Res.. 95. 7937. 1990.

Horwitz, J. L., et al., Plasma boundaries in the inner magnetosphere, J. Geophys. Res., 91, $8861,1986$.

Horwitz, J. L., and N. Singh, Foreward, J. Geophys. Res., 97, 1047, 1992.

Lemaire, J., Plasma distribution models in a rotating magnetic dipole and refilling of plasmaspheric flux tubes, Phys. Fluids B, l, 1519, 1989.

Lennartsson, W., and D. L. Reasoner, Low-energy plasma observations at synchronous orbit, J. Geophys. Res., 83, 2145, 1978.

Lyons, L. R., and D. J. Williams, Quantitative Aspects of Magnetospheric Physics, p. D. Reidel, Dordrecht, Holland, 1984.

Mauk, B. H., and R. L. McPherron, An experimental test of the electromagnetic ion cyclotron instability with the earth's magnetosphere, Phys. Fluids, 23, 2111, 1980.

McComas, D. J., et al., Magnetospheric plasma analyzer: Initial three-spacecraft observations from geosynchronous orbit, J. Geophys. Res., 98, 13453, 1993.

Moldwin, M. B., M. F. Thomsen, S. J. Bame, D. J. McComas, and K. R. Moore, An examination of the structure and dynamics of the outer plasmasphere using multiple geosynchronous satellites, J. Geophys. Res., 99, $11475,1994$.

Nagai, T., J. L. Horwitz, R. R. Anderson, and C. R. Chappell, Structure of the plasmapause from ISEE 1 low-energy ion and plasma wave observations, J. Geophys. Res., 90, 6622, 1985. 
Vishida, A., Formation of plasmapause. or magnetospheric plasma knee. by the combined action of magnetosphere convection and piasma escape from the tail. J. Geophvs. Res.. 71, 5669. 1966.

Olsen. R. C., Equatoriaily trapped plasma populations. J. Geophys. Res.. 36. 11, 1981.

Park. C. G., Whistler observations of the interchange of ionization between the ionosphere and the protonosphere. J. Geophys. Res., 75, 4249. 1970.

Park. C. G., Some features of plasma distribution in the plasmasphere deduced from Antarctic whistlers. J. Geophys. Res., 79. 169, 1974.

Rasmussen, C. E., S. M. Guiter, and S. G. Thomas. A two-dimensional model of the plasmasphere: refilling time constants. Planet. Space Sci. . 4l. 35. 1993.

Reeves, G. D., L. A. Weiss, M. F. Thomsen, and D. J. McComas. A Quantitative Test of Different Magnetic Field Models Using Conjunctions Between DMSP and Geosynchronous Orbit, in Radiation Belt Models and Standards, vol. 97. edited by Lemaire, J. F.. D. Heynderickx and D. N. Baker, p. 167, Am. Geopnys. Union. i 997.

Schulz, M., and H. C. Koons. Thermalization of colliding ion streams beyond the plasmapause, J. Geophys. Res., 77. 248, 1972.

Singh, N., and C. B. Chan, Effects of equatorially trapped ions on refilling of the plasmasphere. J. Geophys. Res., 97, 1167, 1992.

Sojka, J. J., R. W. Schunk, J. F. E. Johnson, J. H. Waite, and C. R. Chappell, Characteristics of thermal and suprathermal ions associated with the day-side plasma trough as measured by the Dynamics Explorer retarding ion mass spectrometer, $J$. Geophys. Res., 88, 7895, 1983.

Sojka, J. J., and G. L. Wrenn, Refilling of geosynchronous flux tubes as observed at the equator by GEOS 2, J. Geophys. Res., 90, 6379, 1985.

Song, X. T., G. Caudal, and R. Gendrin, Refilling of the plasmasphere at the geostationary orbit: A Kp-dependent model deduced from the GEOS-1 measurements of the cold plasma density, Adv. Space Res., 8, 45, 1988.

Spiro, R. W., P. H. Reiff, and L. J. Maher Jr., Precipitating electron energy flux and auroral zone conductances - an empirical model, J. Geophys. Res., 87, 8215, 1982.

Thomsen, M. F., D. J. McComas, G. D. Reeves, and L. A. Weiss, An observational test of the Tsyganenko (T89a) model of the magnetospheric field, J. Geophys. Res., 101, 24, 1996.

Vasyliunas, V. M., A survey of low-energy electrons in the evening sector of the magnetosphere with Ogo 1 and Ogo 3, J. Geophys. Res., 73, 2839, 1968.

Watanabe, S., B. A. Whalen, and A. W. Yau, Thermal ion observations of depletion and refilling in the plasmaspheric trough, J. Geophys. Res., 97, 1081, 1992. 
Weiss. L. A., M. F. Thomsen, G. D. Reeves, and D. J. McComas, Observational Testing of Magnetospheric Field Modeis at Geosynchronous Orbit. p. 93. Space Environment Center, Boulder. Colorado. 1996.

Wilson, G. R., J. L. Horwitz, and J. Lin, A semikinetic model for eariy stage plasmaspheric refilling 1. Effects of coulomb collisions. j. Geophys. Res.. 97. 1109. 1992.

Young, D. T.. S. Perraut. A. Roux, C. de Villedary, R. Gendrin. A. Korth. G. Kremser. and $D$. Jones, Wave-particle interactions near $\Omega_{\mathrm{He}}+$ observed on GEOS $i$ and $2 \mathrm{i}$. Propagation of ion cyclotron waves in He ${ }^{+}$-rich plasma. J. Geophys. Res. 36.6755. 1981.

Figure Captions

Figure 1. (Left) Local time dependence of coid ion density at $L=5$ measured by the Lockheed Light Ion Spectrometer on OGO 5 The symbols indicate the two different procedures that were used to project the measurements to the magnetic equator. and the curves indicate different theoretical expectations [from Chappell et al.. 1971]. (Right) Schematic illustrating the progressive filling of flux tubes as they convect from the night side across the day-side magnetosphere [from Chappell et al., 1971].

Figure 2. Equipotential contours in the magnetospheric equatorial plane for a superposition of the corotational electric field and a uniform, dawn-to-dusk electric field [from Lyons and Williams, 1984].

Figure 3. Schematic summary of the structure of the near-Earth plasma sheet and its relationship to the plasmapause in the midnight region, as observed by OGO 3 [from Frank, 1971]. 
Figure 4. Schematic view of the inner edge of the plasma sheet in the magnetospheric equatorial plane as suggested by Fairfieid and Viñas [1984].

Figure 5. Synthesis view of the ion and electron trougn regions. To lowest order the ion trough (left) and the electron trough (right) are colocated, representing a temporal state in the evolution of convecting flux tubes that are in contact with the earth's !onosphere. Convecting flux tubes progressively lose their electron plasma sheet content to auroral precipitation, while they progressively fill with cold plasma of ionospheric origin.

Figure 6. Schematic trough configuration with circuiar orbits illustrating possible sequences of regions observed by a geosynchronous satellite.

Figure 7. Ion (top) and electron (bottom) measurements made by the MPA onboard 1994-084 on June 17. 1996. Both panels show the color-coded logarithm of the instrument count rate as a function of the logarithm of the particle energy (on the vertical axis) and Universal Time (GMT) on the horizontal axis. The corresponding local times of the measurements are shown below the time axis.

Figure 8. Same as Figure 7 for June 18, 1996.

Figure 9. (Upper panel) Computed densities of low-energy ions $\left(1 \mathrm{eV}<\mathrm{E}_{\mathrm{i}}<100 \mathrm{eV}\right)$ and hot electrons $\left(30 \mathrm{eV}<\mathrm{E}_{\mathrm{e}}<41 \mathrm{keV}\right.$ ) for the 24-hour interval shown in Figure 7. (Lower panel) Corresponding hot-electron energy density (density*temperature). The horizontal bars indicate times when the satellite was between 06 and $18 \mathrm{LT}$.

Figure 10. Same as Figure 7 for June 7, 1996. 
Figure 11. Same as Figure 7 for July 6. 1996, except the eiectron panei shows observations from the eastward-looking spin quadrant. and the color bar has been adjusted to bring out weaker fluxes.

Figure 12. Same as Figure 7 for January 1, 1996.

Figure 13. Local time dependence of the measured density, temperature and energy density of plasma sheet electrons $\left(30 \mathrm{eV}<\mathrm{E}_{\mathrm{e}}<40 \mathrm{keV}\right)$ during the month of January 1990.

Figure 14. Local time dependence of the 5th, 25th. 50th. 75th, and 95th percentile values of the measured plasma sheet energy density in one-hour local-time bins for the month of January 1990 .

Figure 15. Occurrence frequency distributions of the cold ion density $\left(1 \mathrm{eV}<\mathrm{E}_{\mathrm{i}}<100\right.$ $\mathrm{eV})$ for one-hour local-time bins across the day side of the magnetosphere. The measurements were made by the MPA on geosynchronous satellite 1989-046 during the month of July 1990 . The tick marks at the top of each panel indicate the 25 th percentile values.

Figure 16. Local time dependence of the 5 th, 25 th, and 50 th percentile values of the measured cold-ion density in one-hour local-time bins for the month of July 1990. The upper dashed line shows the the trough density at $\mathrm{L}=6.6$ from the model of Carpenter and Anderson [1992]. The lower dashed curve is the Carpenter and Anderson trough density reduced by $0.7 \mathrm{~cm}^{-3}$, to remove approximately the contribution from the hot ion population. 
Figure 17. Twenty-fifth and fiftieth percentile leveis of the coid ion density measured at geosynchronous orbit between 12 and $13 \mathrm{LT}$ for various months covering different seasons and different parts of the soiar cycle. The months are labelled according to the satellite that made the measurements $1046=i 989-046.095=i 990-095.080=i 991-086$. 084=1994-084). 


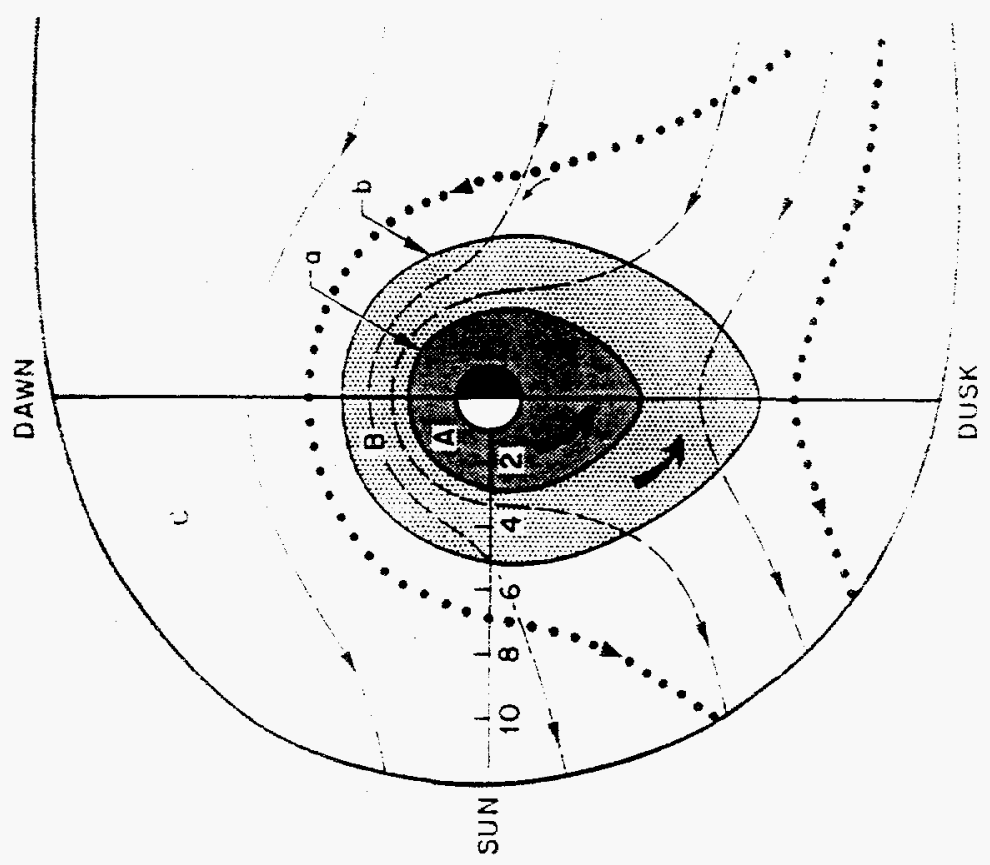

尝

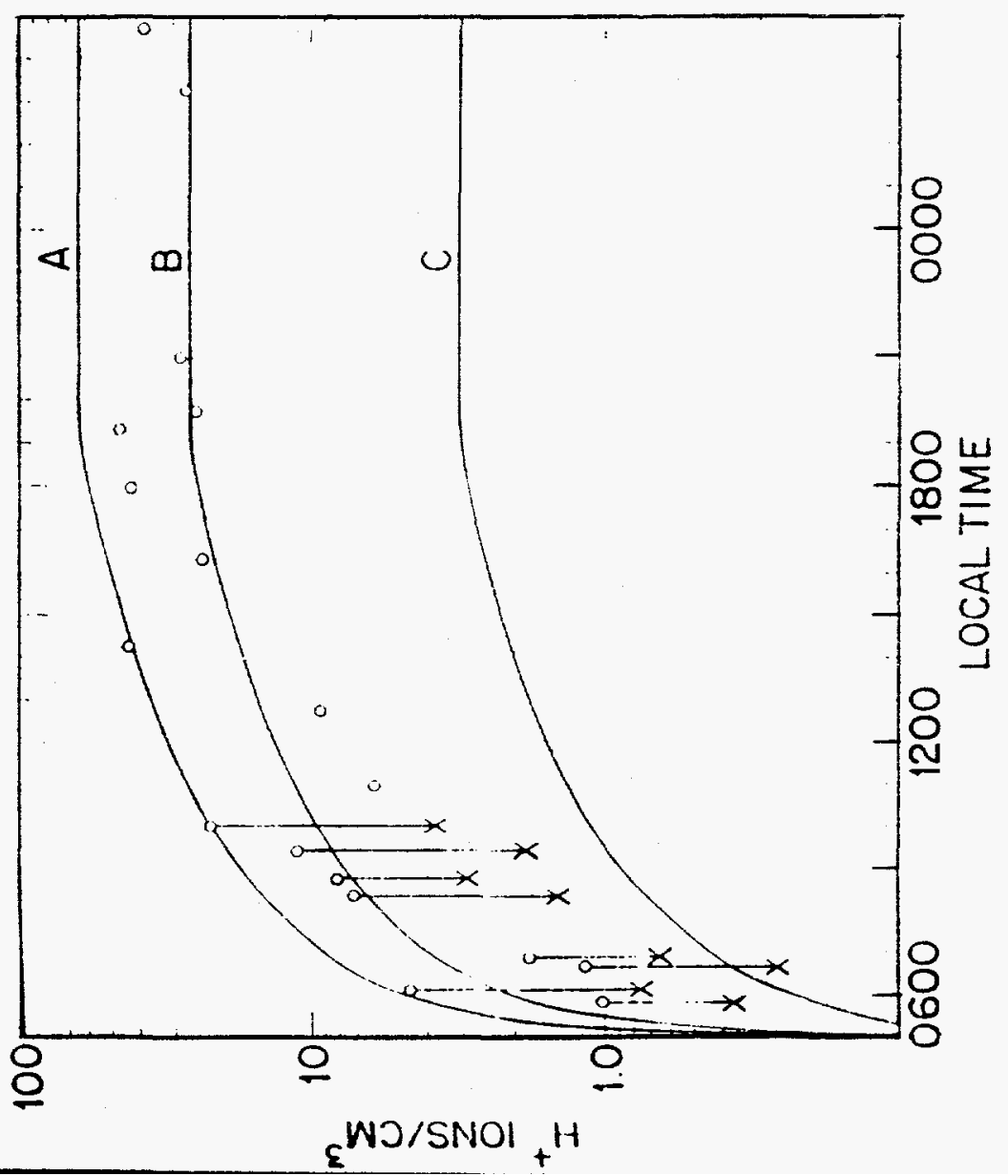




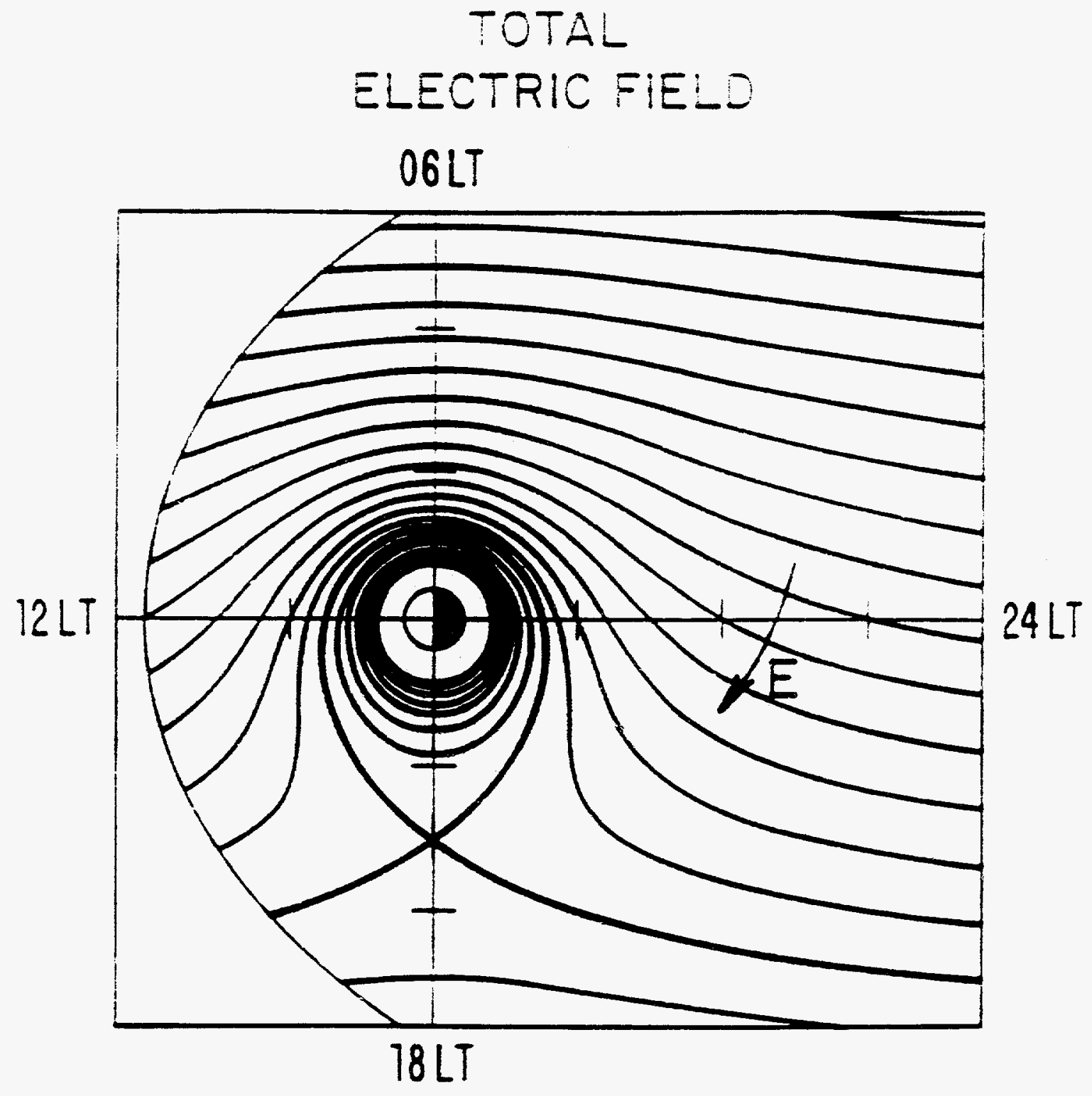

Figure 2 


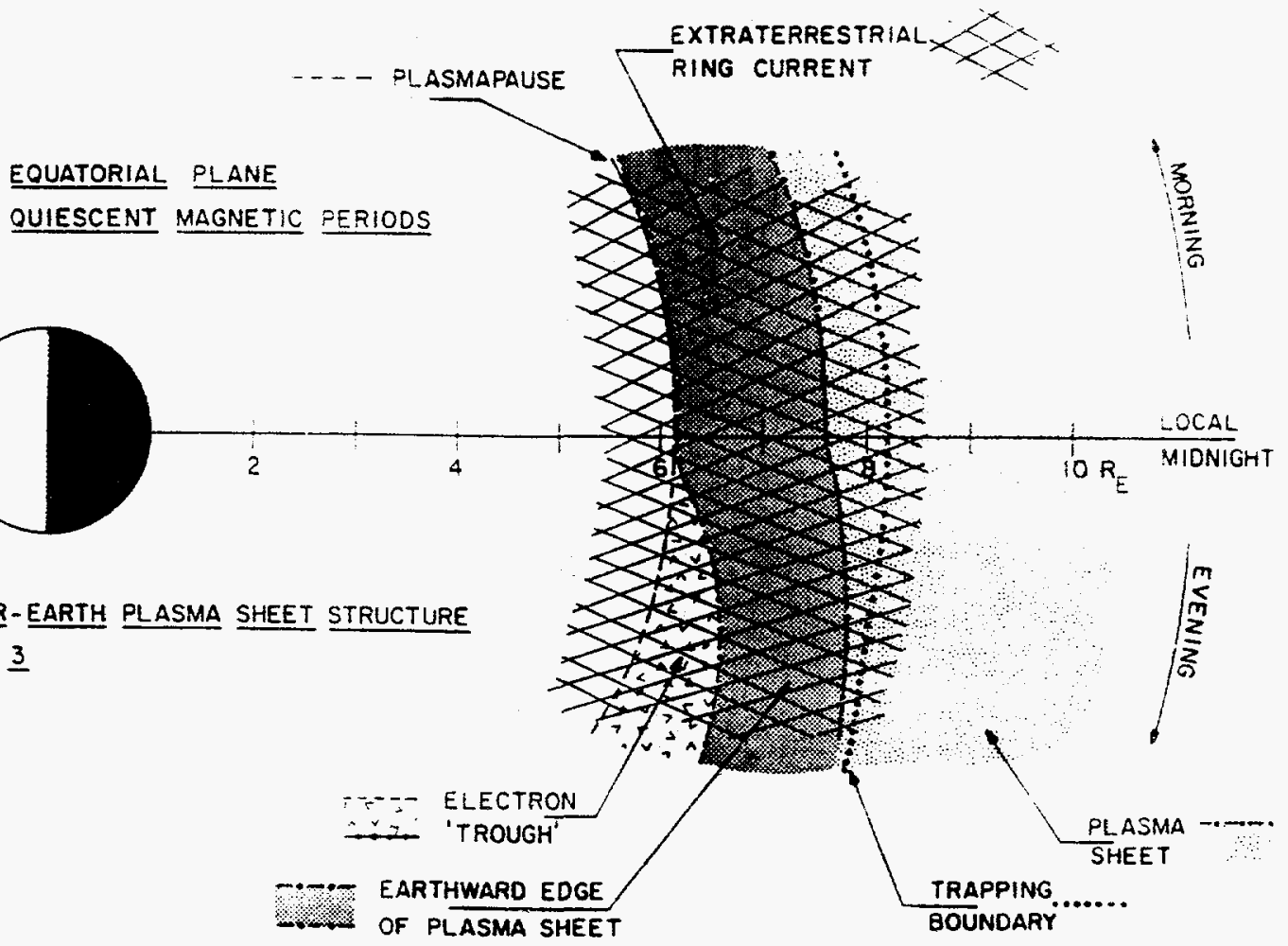

Figure 3 


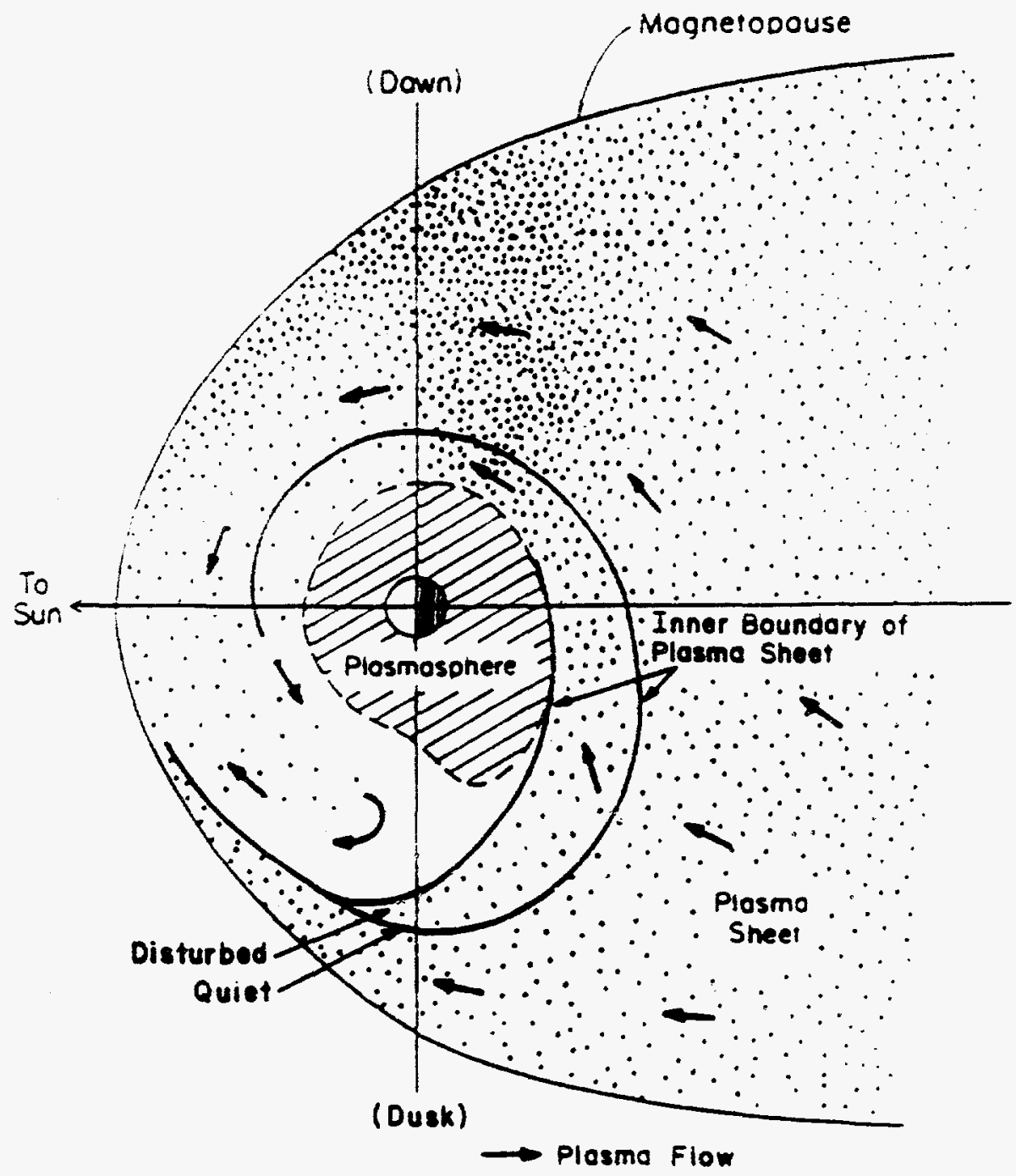

Figure 4 

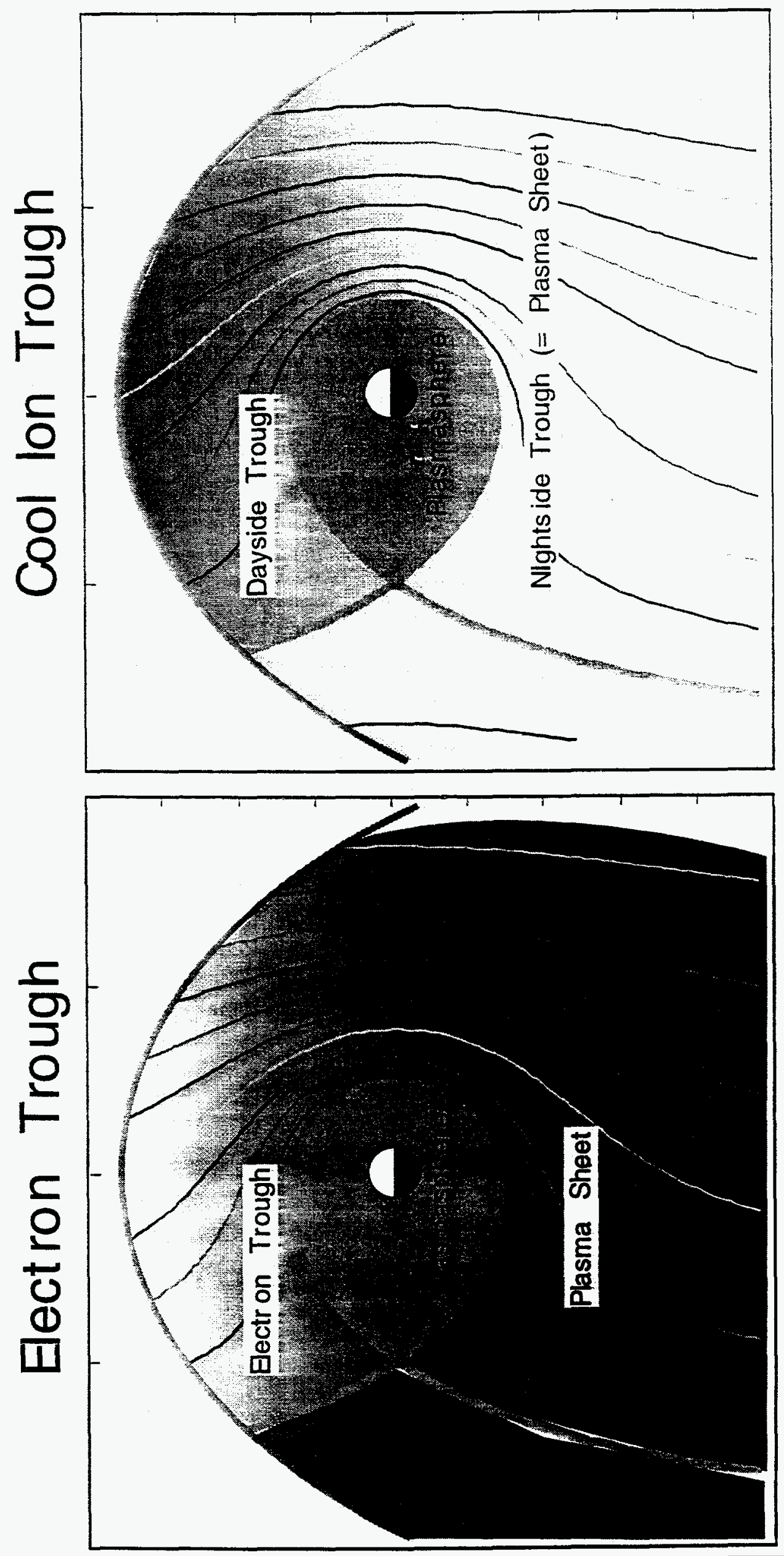

品 

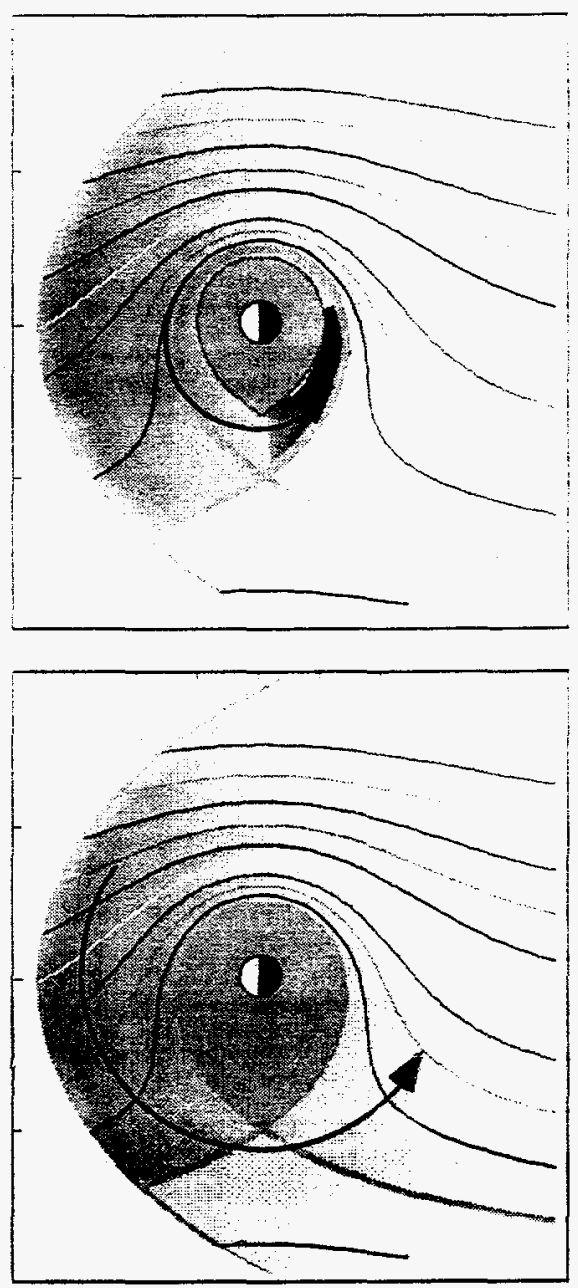

$\frac{0}{2}$

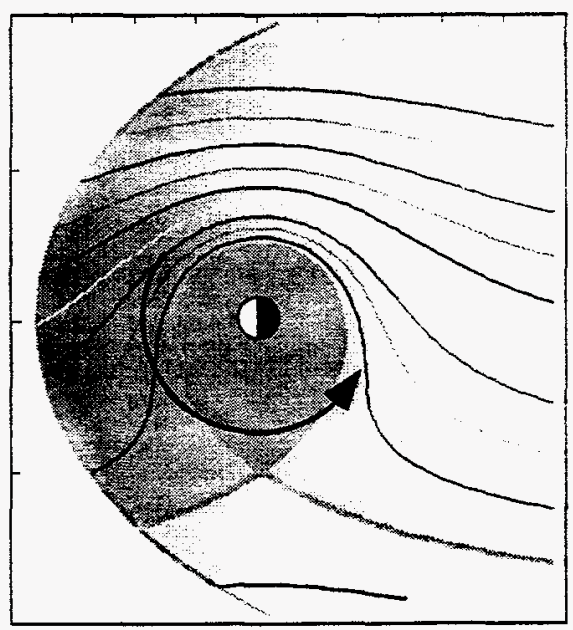




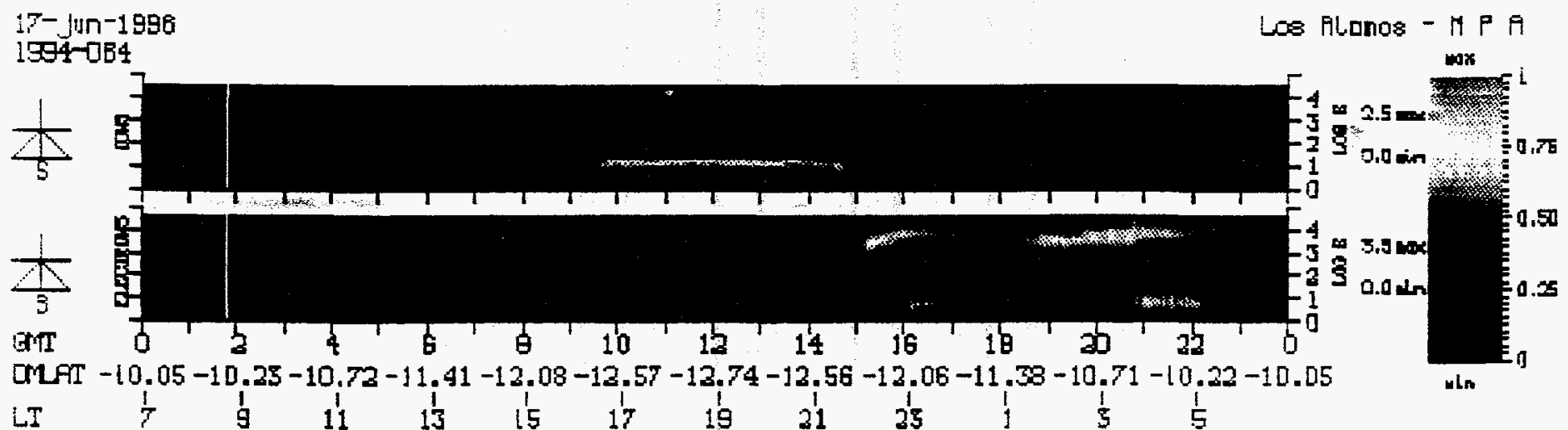

Figure 7. Ion (top) and electron (bottom) measurements made by the MPA onboard 1994-084 on June 17, 1996. Both panels show the color-coded logarithm of the instrument count rate as a function of the logarithm of the particle energy (on the vertical axis) and Universal Time (GMT) on the horizontal axis. The corresponding local times of the measurements are shown below the time axis.

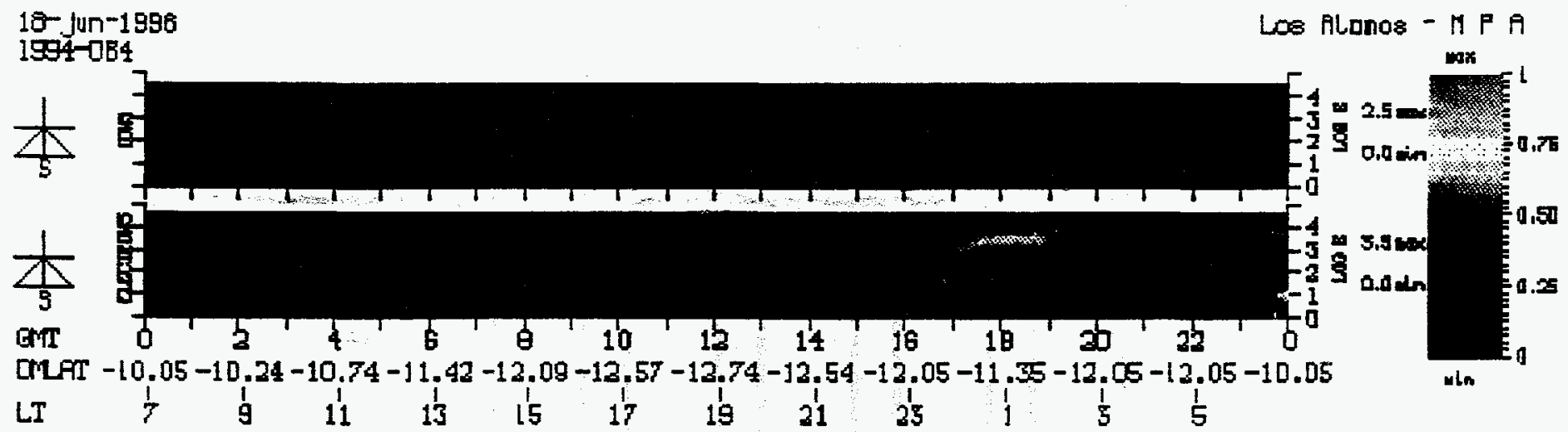

Figure 8. Same as Figure 7 for June i8. 1996. 


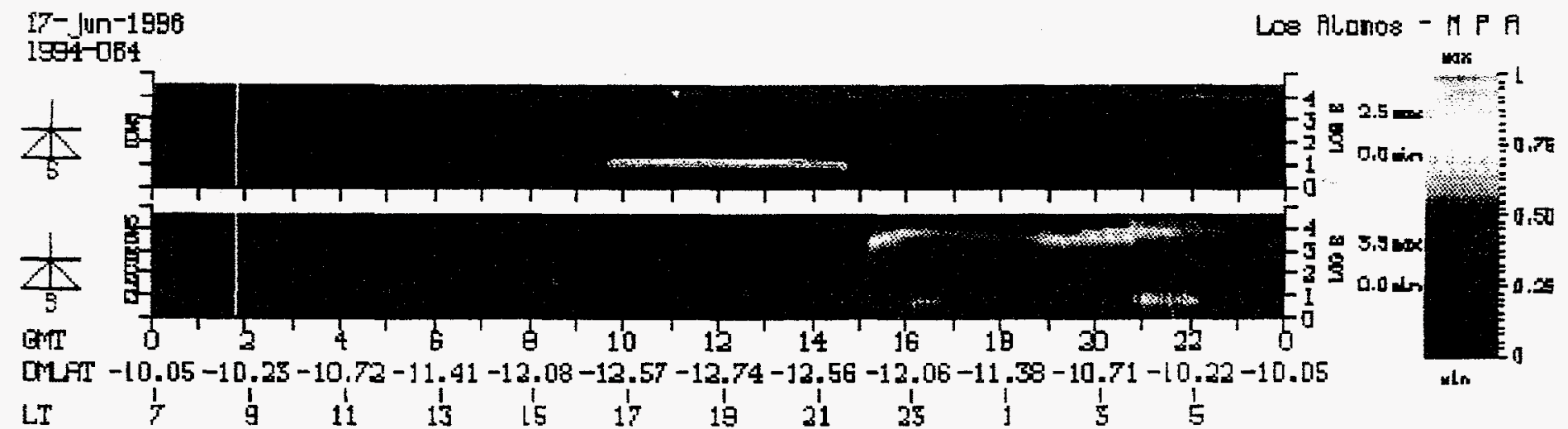

Figure 7. Ion (top) and electron (bottom) measurements made by the MPA onboard 1994-084 on June 17. 1996. Both panels show the color-coded logarithm of the instrument count rate as a function of the logarithm of the particle energy (on the vertical axis) and Universal Time (GMT) on the horizontal axis. The corresponding local times of the measurements are shown below the time axis.

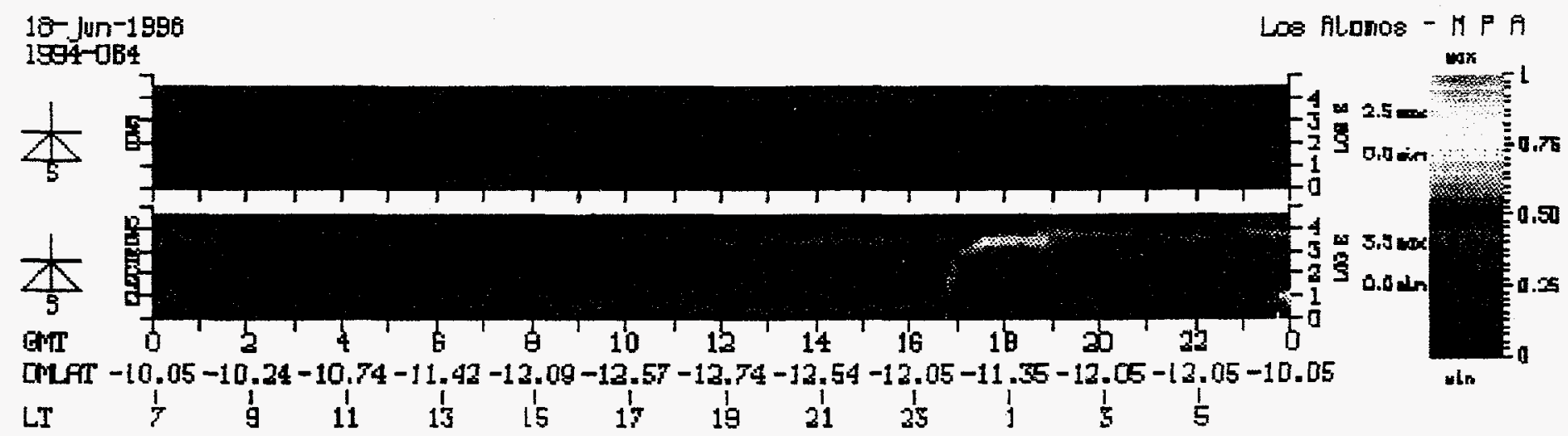

Figure 8. Same as Figure 7 for June 18, 1996. 


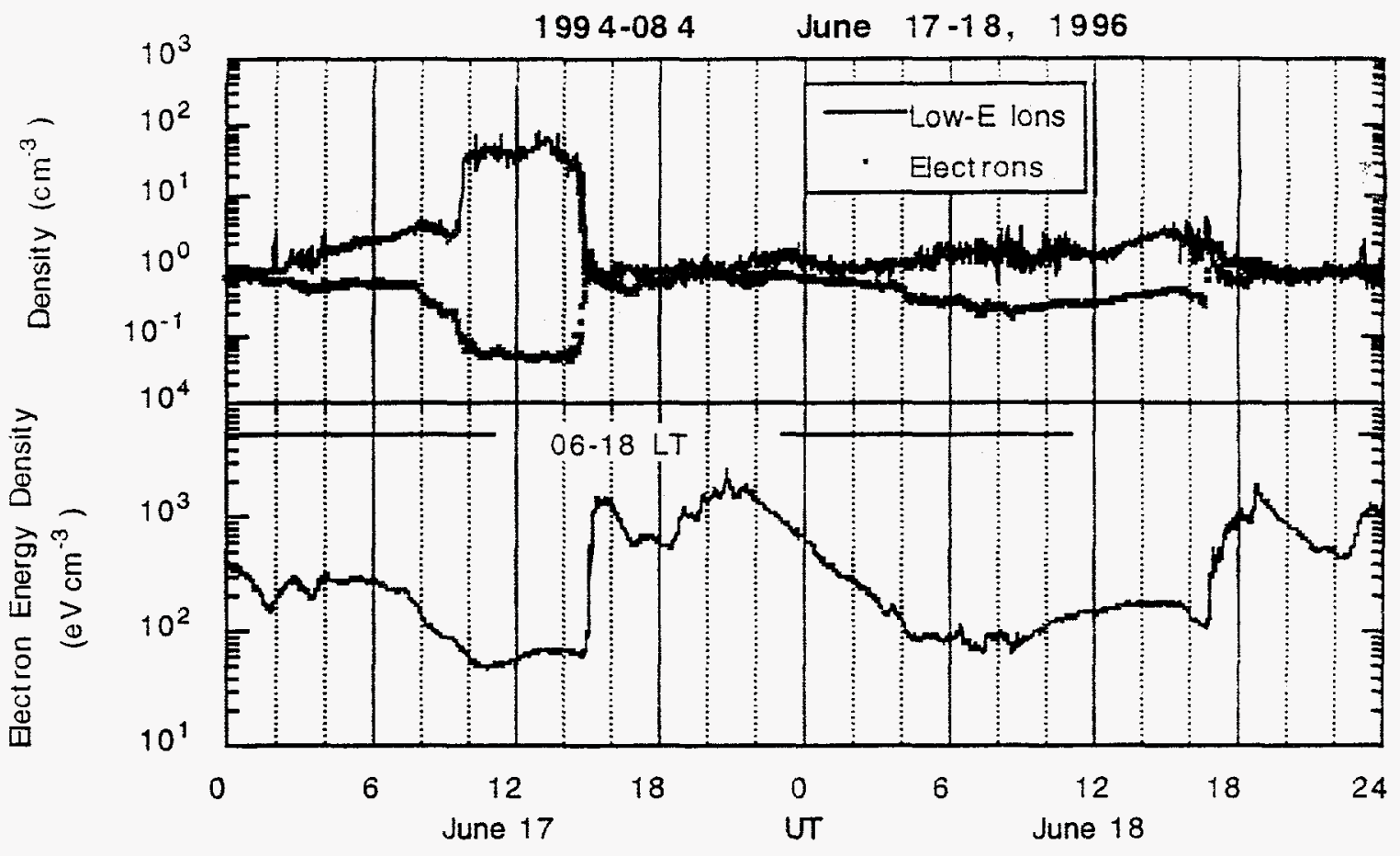

Figure 9 


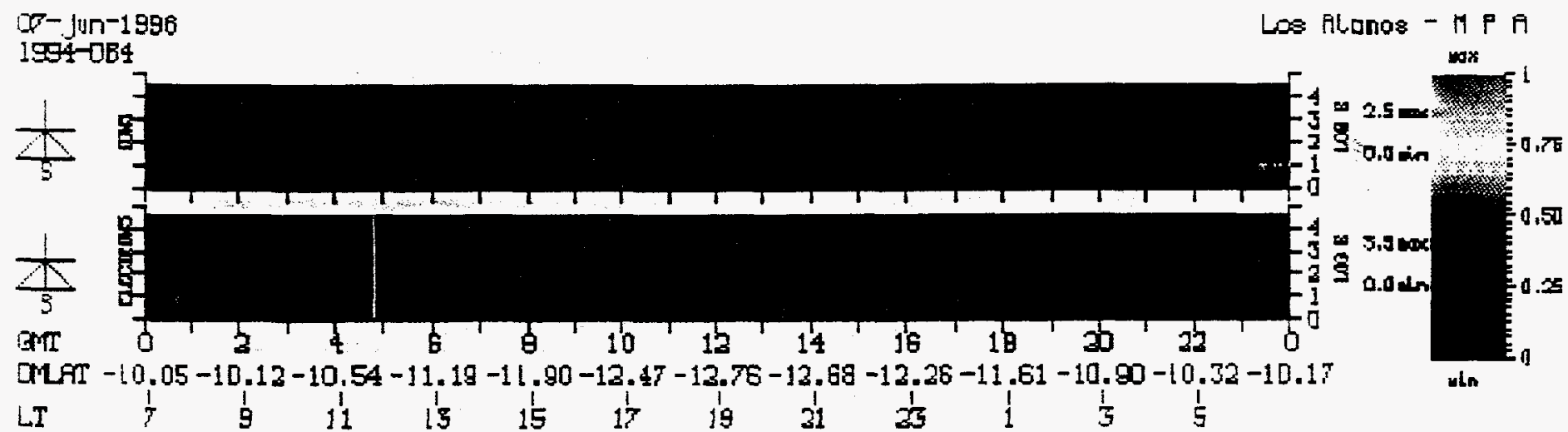

Figure 10. Same as Figure 7 for June 7. 1996.

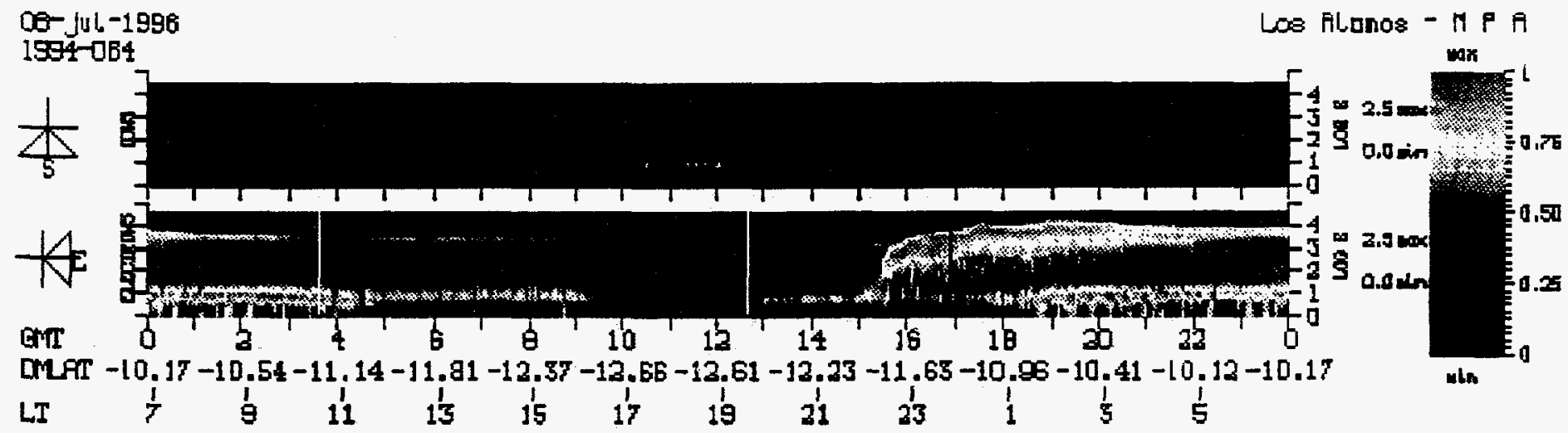

Figure 11. Same as Figure 7 for July 6, 1996, except the electron panel shows observations from the eastward-looking spin quadrant, and the color bar has been adjusted to bring out weaker fluxes.

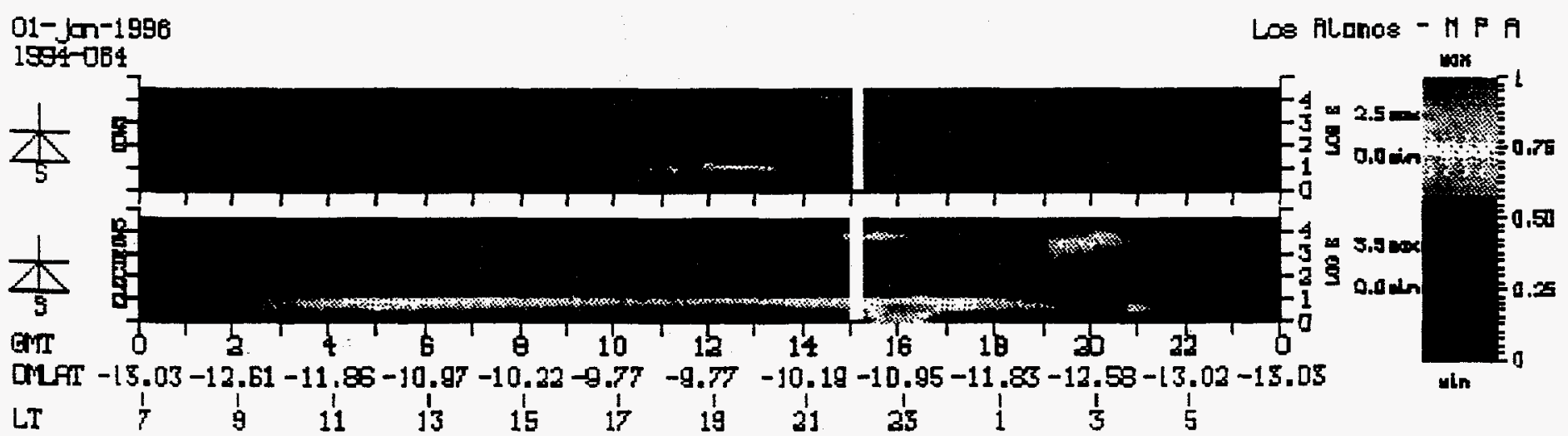

Figure 12. Same as Figure 7 for January 1, 1996. 


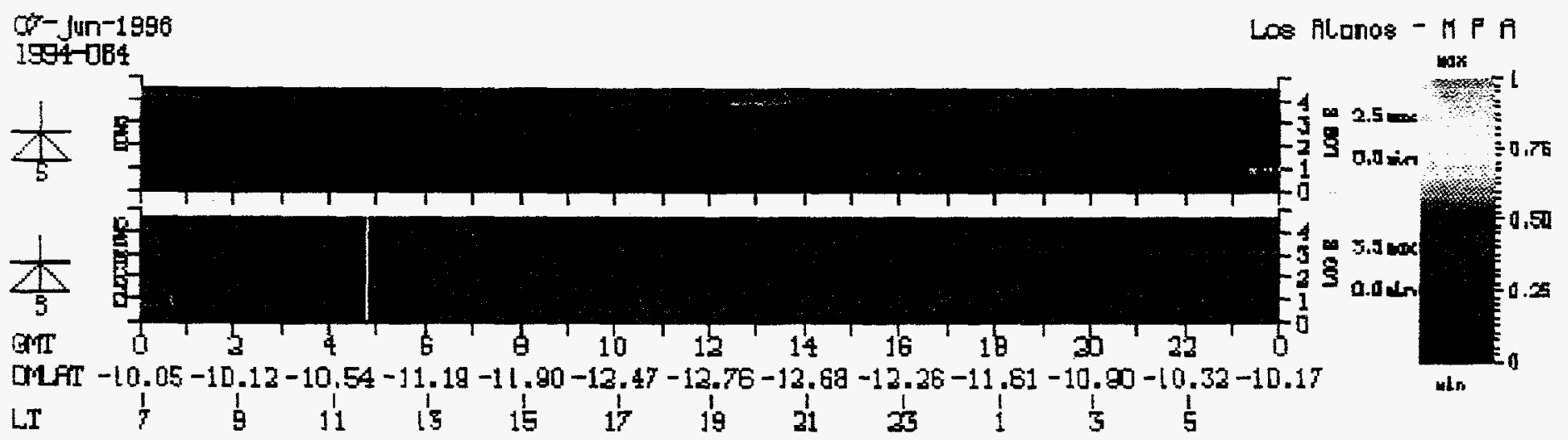

Figure 10. Same as Figure 7 for June 7, 1996.

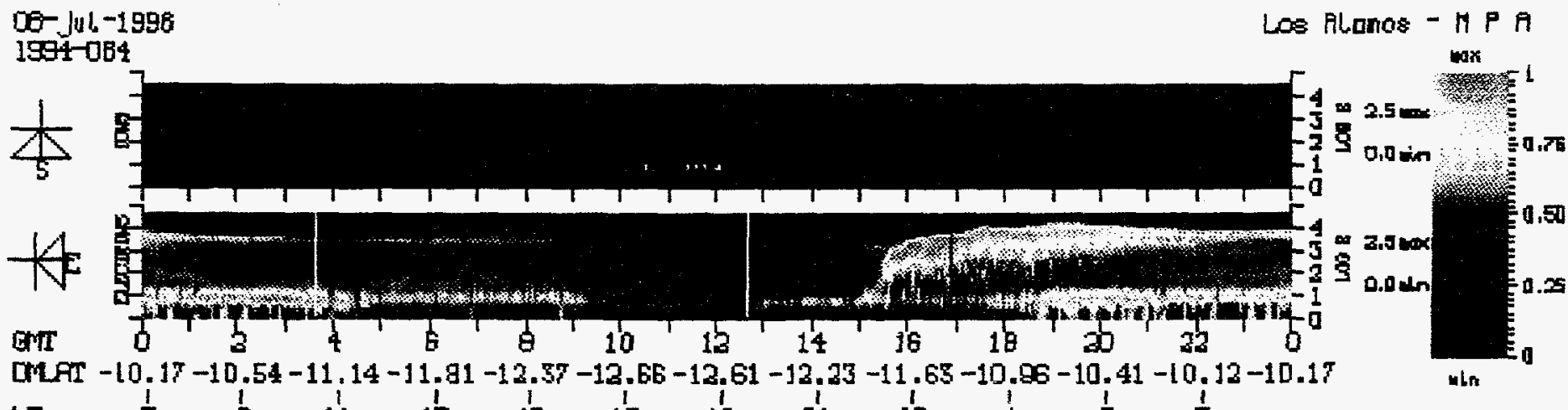

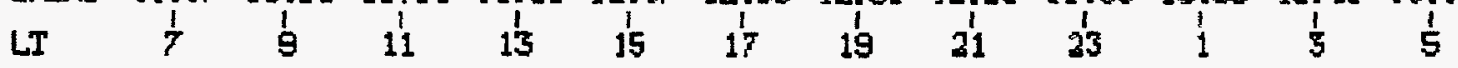

Figure 11. Same as Figure 7 for July 6, 1996, except the electron panel shows observations from the eastward-looking spin quadrant, and the color bar has been adjusted to bring out weaker fluxes.

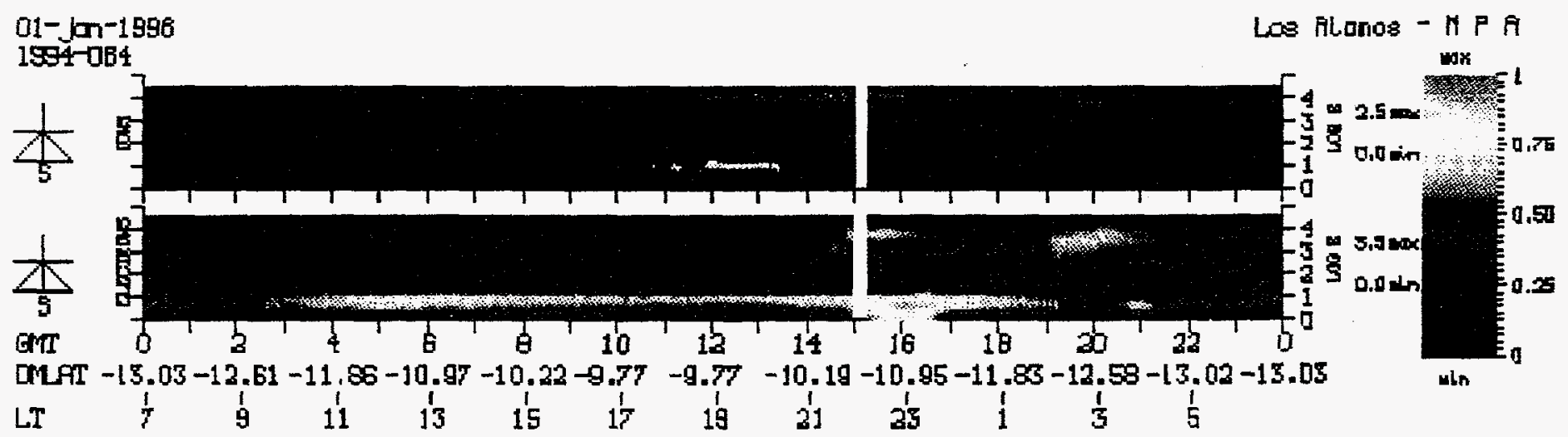

Figure 12. Same as Figure 7 for January 1, 1996. 


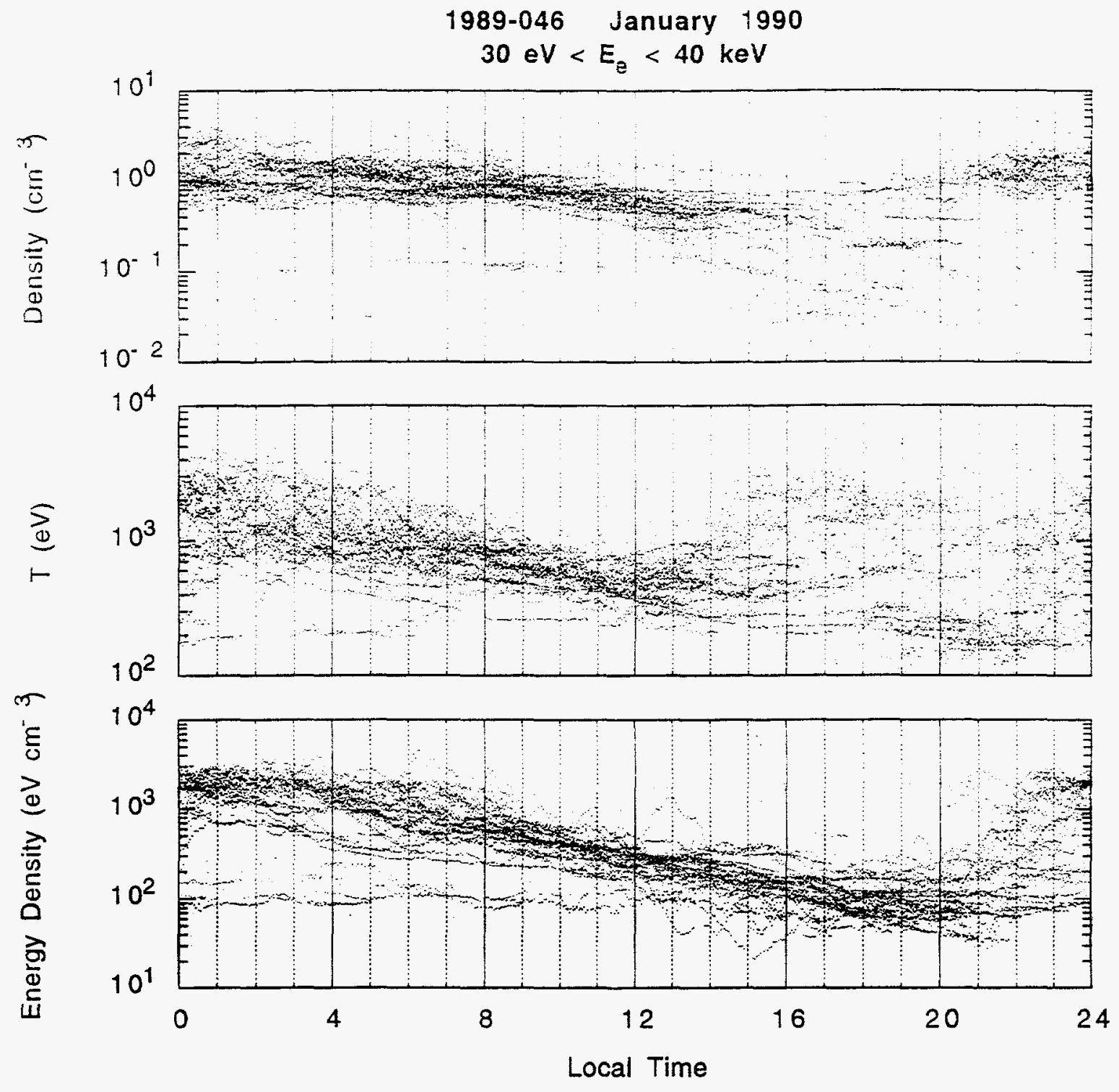

Figure 13 


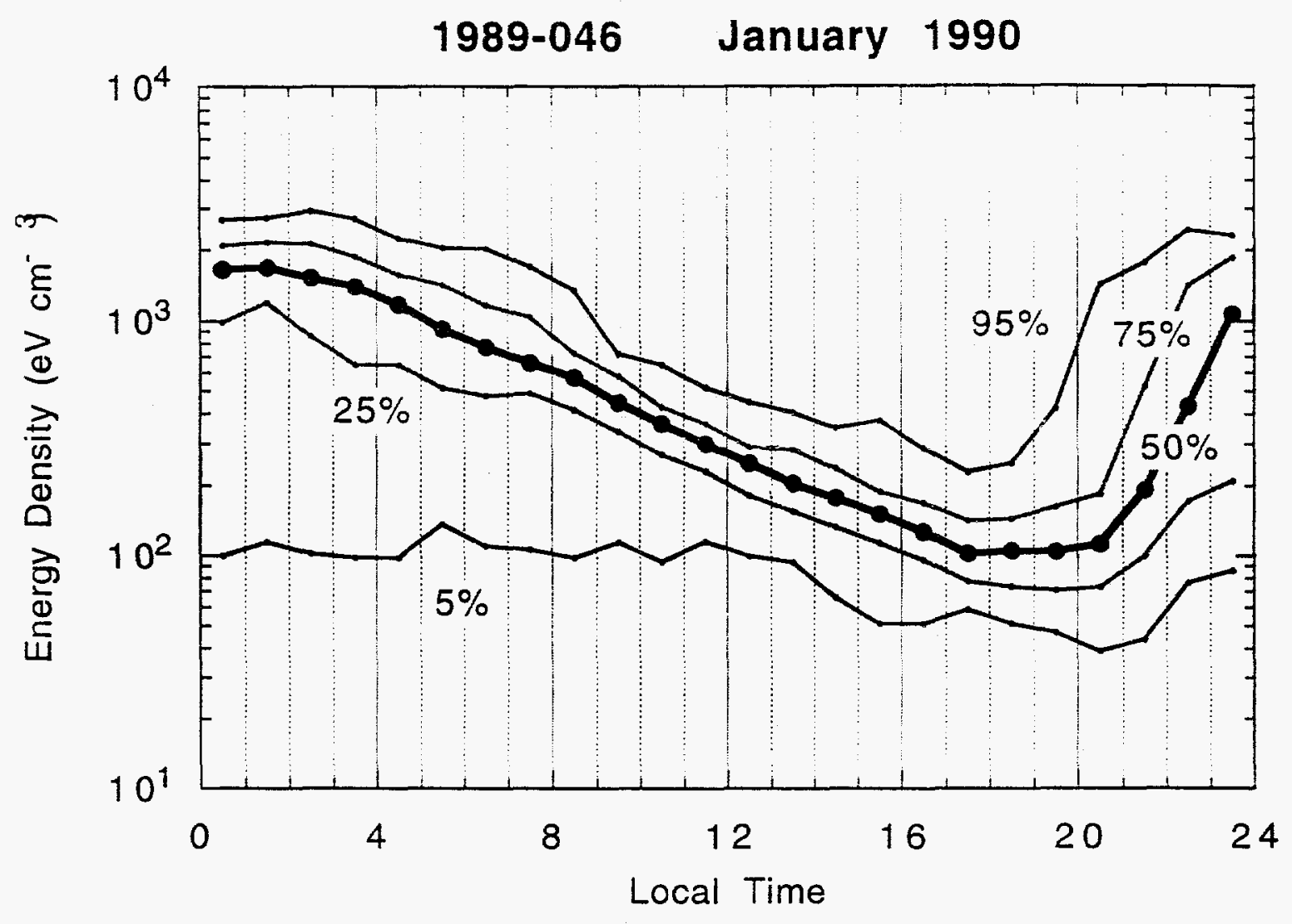

Figure 14 


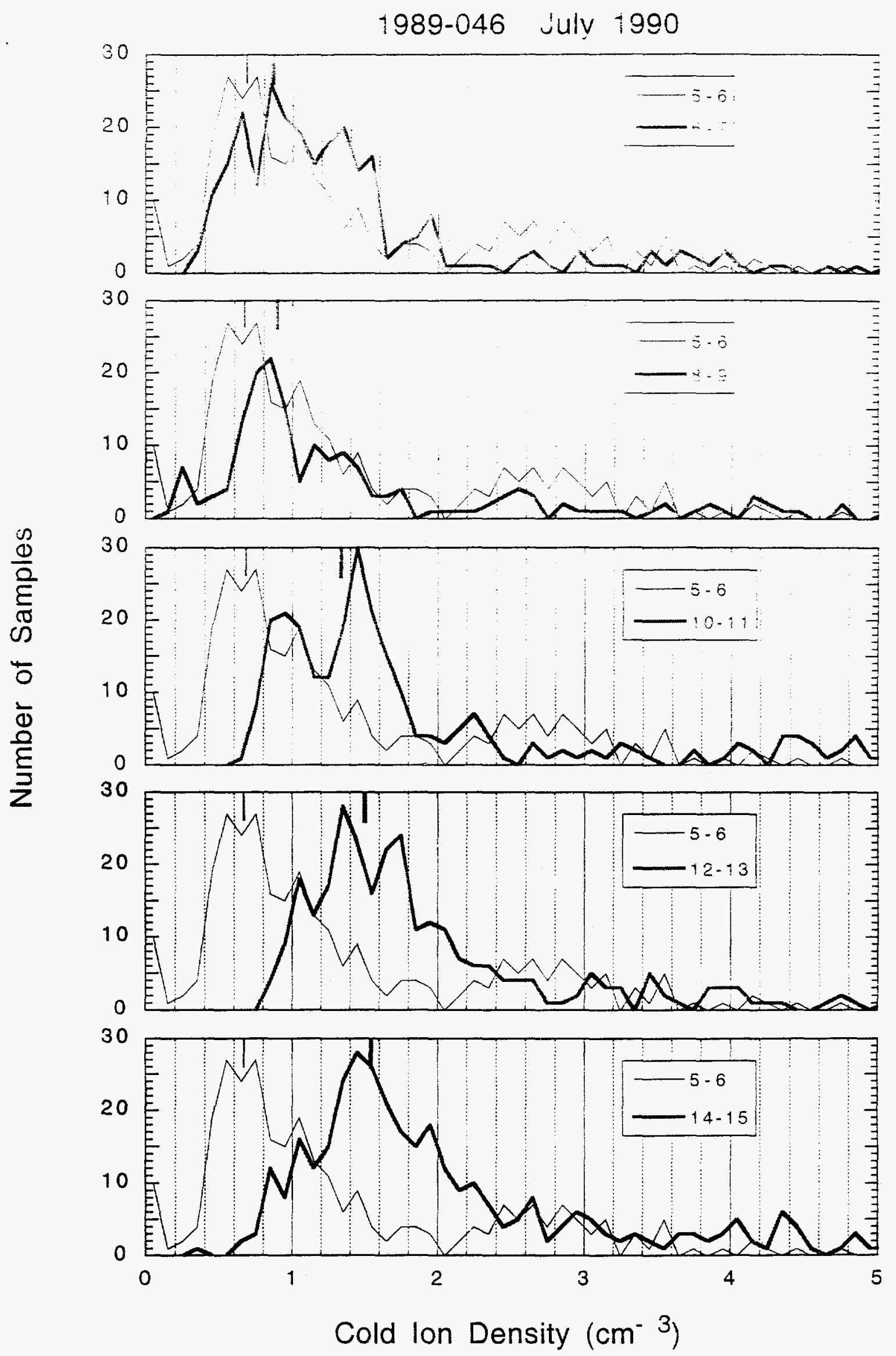

Figure 15 


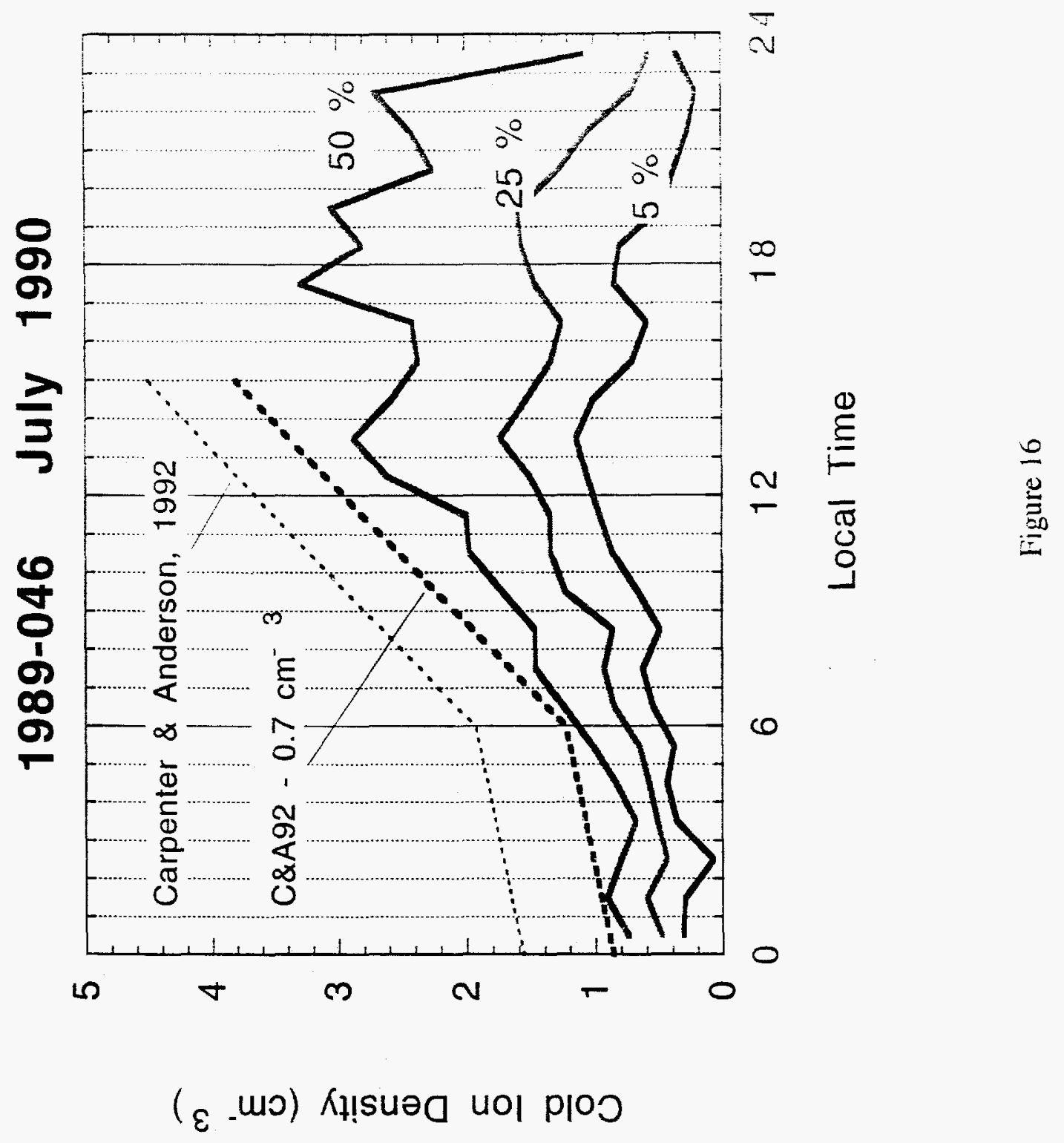


Cold Ion Density $\left(\mathrm{cm}^{-} \beta\right.$

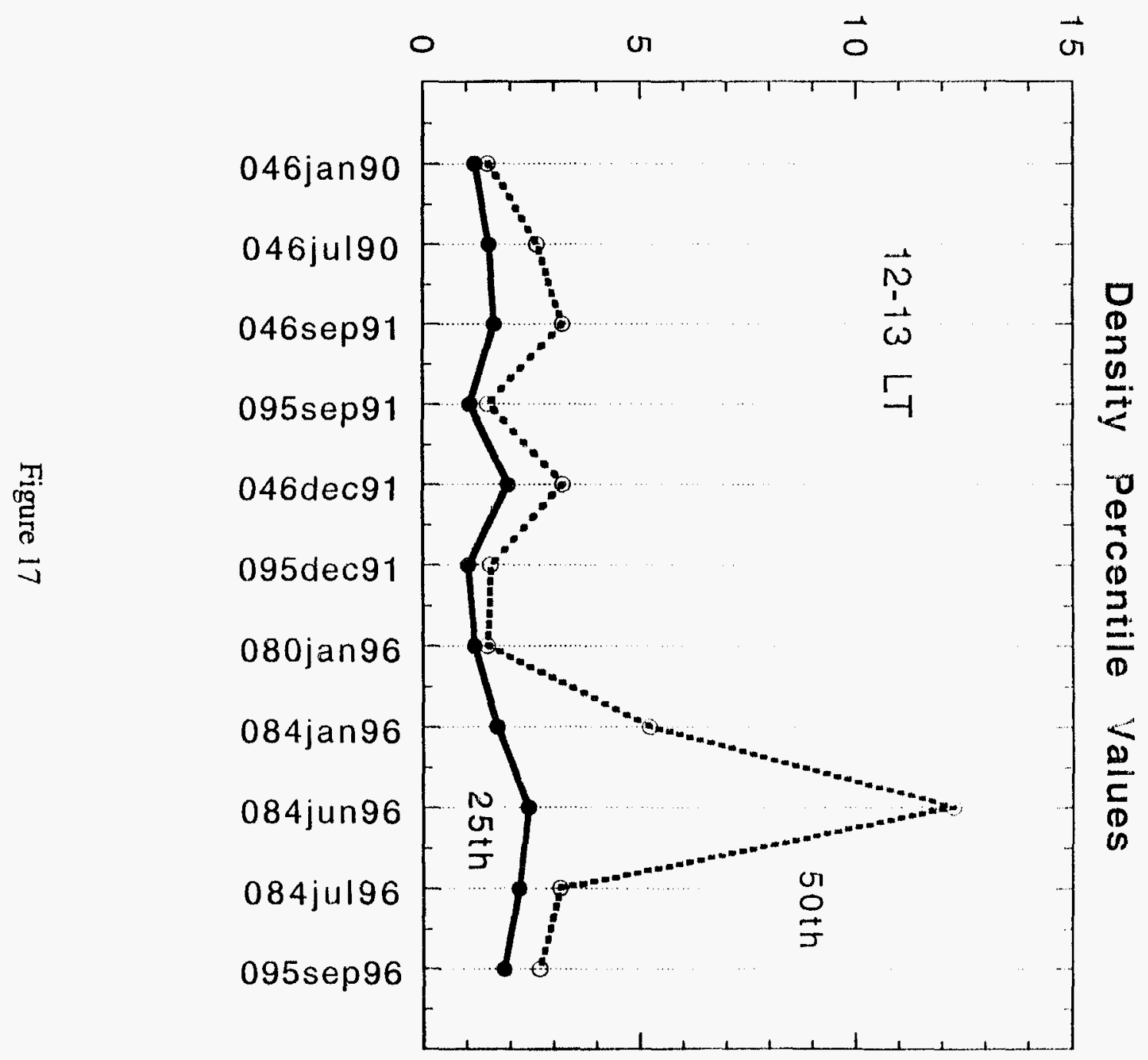

